\title{
Synthesis and Biological Evaluation of Novel Gallic Acid Analogues as Potential Antimicrobial and Antioxidant Agents
}

\author{
Lubna Sherin, ${ }^{1, *}$ Shahida Shujaat, ${ }^{2}$ Ayesha Sohail, ${ }^{3}$ Fatima Arif ${ }^{3}$
}

\author{
${ }_{1}^{1}$ Department of Chemistry, COMSATS University Islamabad, Lahore, Defence Road, Off Raiwind Road, Lahore, 54000, Pakistan \\ 2 Department of Chemistry, Lahore College for Women University, Lahore, 54000, Pakistan \\ 3 Department of Mathematics, COMSATS University Islamabad, Lahore, 54000, Pakistan \\ * Corresponding author's e-mail address: lubnasherin@cuilahore.edu.pk
}

RECEIVED: October 01, 2018 * REVISED: December 28, 2018 * ACCEPTED: January 09, 2019

\begin{abstract}
A series of fifteen novel gallic acid esters (7a-o) was synthesized and structure was confirmed by spectral data. Antibiotic power of compounds was assessed against a panel of ten microbes while antioxidant activity was gauged by employing DPPH, ABTS and antilipid peroxidation assays. It was found that in comparison to lead, many of the synthesized derivatives implied much improved broad spectrum antimicrobial effect. Most effective compound found was 7c specifically against resistant gram-negative strains such as $P$. aeruginosa, E. coli and $E$. aerogenes. Potent antioxidant capacity was exhibited by $7 \mathrm{a}$ and $7 \mathrm{~d}$ in electron transfer assays while $7 \mathrm{j}$ and $7 \mathrm{c}$ provided maximum shielding against lipid peroxidation. Structure-activity analysis revealed that analogues with electron -withdrawing substituent particularly chloro group stand out as much better antibiotic agent. This study suggests that halogenated gallic acid analogues might be promising pharmacological candidates in view of further drug development.
\end{abstract}

Keywords: antimicrobial activity, antioxidant activity, electron-withdrawing substituent, gallic acid esters, structure-activity relationship.

\section{INTRODUCTION}

$\mathbf{M}$ ICROBIAL infections are a serious problem that continues to challenge healthcare sector in both developed and developing countries. Microbes produce a series of diseases ranging from various invasive skin infections to fatal life threatening ailments especially in the patients of organ transplant, acquired immunodeficiency syndrome and cancers. Drug resistance in hospitals and communities has further complicated the treatment. ${ }^{[1]}$ Regardless of advancements in antibiotic therapy, infectious complications are one of the most imperative causes of high rate of morbidity and mortality among hospitalized patients. Under these circumstances there is a dire need for the development of new potent antimicrobials. Owing to enormous chemical and structural diversity, pharmacologically active plant derived natural products that has inspired novel drug discoveries in the past could be a promising source in various medical areas.
Most of the clinical antimicrobial therapeutics are either of natural origin or their semisynthetic derivatives. $[2,3]$

Free radicals mediated oxidative stress has been established as a triggering point for multiple medical conditions such as asthma, arthritis, neurodegenerative disorder, cardiovascular diseases and some cancers via inflammation. ${ }^{[4-6]}$ Additionally, reactive oxygen species (ROS) are major factor in progression of inflammation through the release of cytokines. Antioxidants play key role in management of such conditions by neutralizing active species therefore inversing the oxidative stress. Hence it is very important to search for natural sources of antioxidants to promote public health. It is assumed those natural products or their derivatives, having potent antioxidant activity can relief cellular oxidative stress and may serve as leads for the development of novel drugs or as supplements for the prevention of many diseases. ${ }^{[7]}$

Gallic acid (GA), 3, 4, 5-trihydroxy benzoic acid, is a polyphenolic compound that is exclusively present in plant 
kingdom. It is important bioactive secondary metabolites of various medicinal plants and is widely used in Homeopathic, Ayurveda, Unani and African traditional drug formulations. This natural compound, we isolated from the bark of Terminalia bellerica in continuation of our search for pharmacologically active natural products from native plants, has been speculated as a major contributor of therapeutic power of medicinal plants. According to literature reports, GA has been studied extensively in vitro as well as in vivo for various bioactivities such as antioxidant, antiviral, antibacterial and antifungal, hepatoprotective, neuroprotective, antidiabetic, anticancer against various cell lines, antitumor, analgesic and enzyme inhibition. ${ }^{[8-16]}$ Being biocompatible and environment friendly it has found wide applications in pharmaceutical, food and cosmetic industries. For drug innovation, structural modifications of natural products are necessary as secondary metabolites are produced by the living organisms for self-defense against enemies and environment. Natural product based drug discovery demands manipulation and modification of the structure of active compound to reach drug criterion. In this regard, GA derivatives especially esters have been synthesized and evaluated for various biological activities. For instance alkyl esters of GA with long alkyl chains have shown substantial antioxidant potential.[17] Similarly herpes simplex virus type 1 (HSV-1) was highly susceptible to GA alkyl esters. Cytotoxic potential of gallate esters against B16F10 melanoma cell line was investigated and it was found that they dwindled the strong antioxidant defense of cancer cells and induced apoptosis by elevating oxidative stress within the cells. ${ }^{[18]}$

Inspired by significant antimicrobial and antioxidant activity of GA derivatives, a series of novel gallic acid esters is synthesized in view of to augment its therapeutic power and get better antimicrobial and antioxidant agents. In present work novel alkyl as well as aryl ester derivatives with variable substituent are synthesized and assessed thoroughly against a panel of microbes. Standard antioxidant protocols are employed in consideration to get better antioxidant entities.

\section{EXPERIMENTAL SECTION}

\section{General Experimental Procedures}

Gallenkamp apparatus was used to measure melting points $(\mathrm{mp})$ which are uncorrected. IR spectra were obtained on $\mathrm{KBr}$ plates on FTIR modeIM2000, medacMidac cooperation USA. UV/VIS absorbance was recorded on U-2800 spectrophotometer (Hitachi). Nuclear magnetic resonance (NMR) spectra were recorded on Bruker Avance II 500 spectrometer at $500 \mathrm{MHz}\left({ }^{1} \mathrm{H} \mathrm{NMR}\right), 125.77 \mathrm{MHz}\left({ }^{13} \mathrm{C} \mathrm{NMR}\right)$ in methanol- $\mathrm{d}_{6}$ or $\mathrm{CDCl}_{3}$ containing TMS as internal standard. Mass spectra were obtained on a JEOL JMS-HX110 instrument, in the positive ion mode. Column chromatography (CC) was performed on silica gel (70-230 mesh) from E. Merck. Flash silica CC was done with silica gel $(40-63 \mu \mathrm{m})$ (Silicycle, Canada). Analytical thin layer chromatography (TLC) was performed on TLC plates (silica gel $60 \mathrm{~F}_{254}$, aluminum back, Merck). All the compounds used were either from Sigma-Aldrich (St. Louis, MO, USA) or ACROS ORGANICS. Cell culture media and antibiotics were obtained from GIBCO while microbial culture media and antibiotics were gained from Oxiod (Basingstoke, UK). All solvents were obtained from Merck and distilled before use except HPLC grade solvents.

\section{Derivatization of Gallic acid $(3,4,5$ - trihydroxybenzoic acid)}

\section{Synthesis of Propyl 3, 4, 5-trihydroxybenzoate (2) ${ }^{[19]}$}

Propyl 3,4,5-trihydroxybenzoate was prepared by dissolving GA (1) (1.0 g, $5.8 \mathrm{mmol})$ in propyl alcohol (15.0 $\mathrm{ml})$ in a single neck round bottom flask. Thionyl chloride $(0.9 \mathrm{ml}, 2.4 \mathrm{mmol})$ was added dropwise along with stirring at $0^{\circ} \mathrm{C}$. Reaction mixture was refluxed at $70^{\circ} \mathrm{C}$ for $5-6 \mathrm{~h}$ under nitrogen atmosphere and monitored by TLC. Solid product was obtained by removing solvent with the help of rotary evaporator. It was redissolved in EtOAc and washed with $\mathrm{NaHCO}_{3}$ solution $(3 \times 20.0 \mathrm{ml})$, brine solution $(2 \times 20.0$ $\mathrm{ml}$ ) and finally with water. EtOAc layer was dried over sodium sulphate and then under nitrogen at rt. Pure propyl 3, 4, 5-trihydroxy benzoate was obtained by a column wash using Pet ether :EtOAc $(1: 1)$ solvent mixture. m.p. 146-148 ${ }^{\circ} \mathrm{C}$; yield: $73 \%$; IR $(\mathrm{KBr}), \tilde{u} / \mathrm{cm}^{-1}$ : $3445(\mathrm{OH}), 3030\left(\mathrm{sp}^{2} \mathrm{CH}\right)$, $1740(\mathrm{C}=\mathrm{O}), 1625,1495$ (C=C), 1240 (C-O); ${ }^{1} \mathrm{H}$ NMR (methanol- $\mathrm{d}_{6}, 500 \mathrm{MHz}$ ) $\delta /$ ppm: $1.04\left(\mathrm{t}, 3 \mathrm{H}, \mathrm{J}=7.4 \mathrm{~Hz}, \mathrm{CH}_{3}\right.$ ), $\left.1.77\left(\mathrm{~m}, 2 \mathrm{H}, \mathrm{CH}_{2}\right), 4.2 \mathrm{(t}, 2 \mathrm{H}, J=6.6 \mathrm{~Hz}, \mathrm{OCH}_{2}\right), 7.08(\mathrm{~s}, 2 \mathrm{H}$, $\mathrm{H}_{2} \& \mathrm{H}_{6}$ ); ${ }^{13} \mathrm{C}$ NMR (methanol-d $6,125 \mathrm{MHz}$ ) $\delta / p p m: 10.12$ $\left(C_{10}\right), 22.59\left(C_{9}\right), 67.13\left(C_{8}\right), 110.67\left(C_{2} / C_{6}\right), 122.45\left(C_{1}\right)$, $139.54\left(C_{4}\right), 146.81\left(C_{3} / C_{5}\right), 167.26\left(C_{7}\right)$;HR-ESI-MS: $m / z=$ $213.40[\mathrm{M}+\mathrm{H}]^{+}$.

Synthesis of Propyl 3, 4, 5-tribenzyloxybenzoate (3) ${ }^{[20]}$ Benzyl chloride $(4.6 \mathrm{ml}, 40.0 \mathrm{mmol})$ was added to a solution of compound $2\left(2.2 \mathrm{~g}, 1.0 \times 10^{-5} \mathrm{mmol}\right)$ in DMF $(20.0 \mathrm{ml})$ in a three necks round bottom flask. Potassium carbonate (5.0g, $\left.3.6 \times 10^{-5} \mathrm{mmol}\right)$ was mixed with continuous stirring to reaction mixture and it was refluxed on an oil bath for 4 h. Water $(40.0 \mathrm{ml})$ was then poured in the mixture and cooled in ice. Crude product was filtered and dried under nitrogen. Recrystallization of crude product by Hex : benzene (1:2) gave pure colorless powder of propyl-3, 4, 5tribenzyloxybenzoate. m.p. $150-152^{\circ} \mathrm{C}$; yield: $73 \%$; IR (KBr) $\tilde{u} / \mathrm{cm}^{-1}: 3020$ (sp $\left.{ }^{2} \mathrm{CH}\right), 1738$ (C=O), 1610, 1490 (C=C), 1240 (C-O); ${ }^{1} \mathrm{H} \mathrm{NMR}\left(\mathrm{CDCl}_{3}, 500 \mathrm{MHz}\right) \delta / \mathrm{ppm}: 0.88(\mathrm{t}, 3 \mathrm{H}, J=7.4$ $\left.\mathrm{Hz}, \mathrm{CH}_{3}\right), 1.64\left(\mathrm{q}, 2 \mathrm{H}, J=6.8 \mathrm{~Hz}, \mathrm{CH}_{2}\right), 4.12(\mathrm{t}, 2 \mathrm{H}, J=6.7 \mathrm{~Hz}$, 
$\left.\mathrm{OCH}_{2}\right), 5.00\left(\mathrm{~d}, 6 \mathrm{H}, J=6.8 \mathrm{~Hz}, \mathrm{OCH}_{2} \times 3\right), 7.26(\mathrm{~m}, 17 \mathrm{H}, \mathrm{ArH})$;

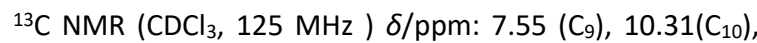
$22.78\left(\mathrm{C}_{8}\right), 71.23\left(\mathrm{O}-\mathrm{CH}_{2}\right), 109.78\left(\mathrm{C}_{2} / \mathrm{C}_{6}\right), 124.52\left(\mathrm{C}_{1}\right)$, $127.21\left(C_{2^{\prime}} / C_{6^{\prime}}\right), 127.79\left(C_{4^{\prime}}\right), 129.45\left(C_{3^{\prime}} / C_{5^{\prime}}\right), 136.85\left(C_{1^{\prime}}\right)$, $143.24\left(C_{4}\right), 152.67\left(C_{3} / C_{5}\right), 167.78\left(C_{7}\right)$; HR-ESI-MS: $m / z=$ $213.27[\mathrm{M}+\mathrm{H}]^{+}$.

Synthesis of 3,4,5-tribenzyloxybenzoic acid (4)[20] Sodium hydroxide $(0.42 \mathrm{~g}, 10.5 \mathrm{mmol})$ was added in three portions to a solution of compound $3(1.5 \mathrm{~g}, 3.5 \mathrm{mmol})$ in methanol $(40.0 \mathrm{ml})$. Water $(2.0 \mathrm{ml})$ was added and refluxed on an oil bath for $4 \mathrm{~h}$. It was cooled and water $(100 \mathrm{ml})$ was added again, followed by acidification with $\mathrm{HCl}(36 \%)$. Product was filtered, washed with water and recrystallized with ethanol to get 3,4,5-tribenzyloxybenzoic acid. Synthesized compound was obtained as colorless powder. m.p. $188^{\circ} \mathrm{C}$; yield, $85 \%$; IR (KBr) ṽ $/ \mathrm{cm}^{-1}$ : $3485(\mathrm{OH}), 3010$ $\left(\mathrm{sp}^{2} \mathrm{CH}\right), 1705(\mathrm{C}=\mathrm{O}), 1600,1490(\mathrm{C}=\mathrm{C}) ;{ }^{1} \mathrm{H}$ NMR $\left(\mathrm{CDCl}_{3}, 500\right.$ $\mathrm{MHz}$ ) $\delta / \mathrm{ppm}: 4.96$ (d, $\left.6 \mathrm{H}, J=4.2 \mathrm{~Hz}, \mathrm{OCH}_{2}\right), 6.82\left(\mathrm{~s}, 2 \mathrm{H}, \mathrm{H}_{2}\right.$ \& $\left.\mathrm{H}_{6}\right), 7.07(\mathrm{~s}, 15 \mathrm{H}, \mathrm{ArH}) ;{ }^{13} \mathrm{C} \mathrm{NMR}\left(\mathrm{CDCl}_{3}, 125.0 \mathrm{MHz}\right)$ 8/ppm: $72.27\left(\mathrm{OCH}_{2} \times 2\right), 71.43\left(\mathrm{OCH}_{2}\right), 110.78\left(\mathrm{C}_{2} / \mathrm{C}_{6}\right)$, $127.23\left(C_{2^{\prime}} / C_{6^{\prime}}\right), 128.42\left(C_{4^{\prime}}\right), 128.92\left(C_{3^{\prime}} / C_{5^{\prime}}\right), 141.27\left(C_{1^{\prime}}\right)$, $145.34\left(C_{4}\right), 151.62\left(C_{3} / C_{5}\right), 170.56\left(C_{7}\right)$; HR-ESI-MS: $m / z=$ $441.52[\mathrm{M}+\mathrm{H}]^{+}$.

\section{Synthesis of 3, 4, 5-tribenzyloxybenzoyl chloride (5) ${ }^{[20]}$} Compound 4 (1.23 g, $2.8 \mathrm{mmol}$ ) and thionyl chloride (95 $\%, 4.2 \mathrm{ml}, 58.0 \mathrm{mmol})$ were added to benzene $(25.0 \mathrm{ml})$ in a completely dried flask. Pyridine $(0.5 \mathrm{ml})$ was poured in the solution while stirring. Reaction mixture was refluxed for $3 \mathrm{~h}$ at $73{ }^{\circ} \mathrm{C}$. Petroleum ether was added to this mixture and concentrated on rotary evaporator. This concentrated acid chloride was diluted with $10.0 \mathrm{ml}$ chloroform and used immediately for coupling with respective alcohol or aniline.

\section{General Protocol for Gallic Acid Esters Synthesis (6a-6o)}

Ester derivatives were synthesized according to the reported procedure. ${ }^{[21]}$ One half of the diluted solution of compound $\mathbf{5}(\approx 1 \mathrm{mmol})$ was added immediately after synthesis to the ice cold solution of respective coupling alcohol $(1.5 \mathrm{mmol})$ and triethylamine $(3.0 \mathrm{mmol})$ in anhydrous chloroform $(20.0 \mathrm{ml})$. It was brought to $\mathrm{rt}$, followed by refluxing. TLC monitoring of the reaction was done with solvent system Pet. ether : Ethyl acetate $(1: 1)$. On completion, organic layer was washed with $\mathrm{NaHCO}_{3}$ solution $(3 \times 20.0 \mathrm{ml})$, brine solution $(2 \times 20.0 \mathrm{ml})$ and finally with water $(2 \times 20.0 \mathrm{ml})$, followed by drying over sodium sulphate. Solvent was removed by rotary evaporator and pure product was obtained by CC (Hex : EtOAc $8: 2$ ).

\section{Debenzylation of Gallic Acid Esters $(7 a-70)^{[22]}$}

In an oven-dried round bottom flask, benzylated ester (6a6o, $1.0 \mathrm{mmol}$ ) was dissolved in solvent mixture of chloroform and methanol (1:1). Palladium/ activated carbon $(10.0 \% \mathrm{Pd}, 50.0 \mathrm{mg}$ ) were added to it. Air was evacuated from the flask by vacuum and reaction mixture was stirred at $\mathrm{rt}$ under hydrogen atmosphere. It was monitored by TLC using solvent system Hex : EtOAc (1:1). On completion, reaction mixture was filtered on celite and dried in rotary evaporator. Pure product was obtained by CC (Hex : EtOAc 9:1 $\rightarrow$ 8:2).

Spectroscopic data of the synthesized analogues is listed below.

\section{2,2,2-trichloroethyl 3, 4, 5-trihydroxybenzoate (7a)}

IR (KBr) v $/ \mathrm{cm}^{-1}: 3510(\mathrm{OH}), 3010$ (sp $\left.{ }^{2} \mathrm{CH}\right), 1739$ (C=O), 1625 $(\mathrm{C}=\mathrm{C}), 1201(\mathrm{CO}) ;{ }^{1} \mathrm{H}$ NMR (methanol- $\mathrm{d}_{6}, 500 \mathrm{MHz}$ ) $\delta / \mathrm{ppm}$ : $4.86\left(\mathrm{~s}, 2 \mathrm{H}, \mathrm{CH}_{2}\right), 6.80\left(\mathrm{~s}, 2 \mathrm{H}, \mathrm{H}_{2} \& \mathrm{H}_{6}\right) ;{ }^{13} \mathrm{C}$ NMR (methanol$\left.\mathrm{d}_{6}, 125 \mathrm{MHz}\right)$ / $/ \mathrm{ppm}: 75.82\left(\mathrm{C}_{8}\right), 96.26\left(\mathrm{C}_{9}\right), 110.41\left(\mathrm{C}_{2} \&\right.$ $\left.C_{6}\right), 125.17\left(C_{1}\right), 140.74\left(C_{4}\right), 148.37\left(C_{3} \& C_{5}\right), 164.19\left(C_{7}\right)$; HR-ESI-MS: $m / z=302.59[\mathrm{M}+\mathrm{H}]^{+}$.

\section{3-bromopropyl 3, 4, 5-trihydroxybenzoate (7b)}

IR ( $\mathrm{KBr}) \tilde{u} / \mathrm{cm}^{-1}$ : $3495(\mathrm{OH}), 3010\left(\mathrm{sp}^{2} \mathrm{CH}\right), 2900\left(\mathrm{sp}^{3} \mathrm{CH}\right)$, $1739(\mathrm{C}=\mathrm{O}), 1619(\mathrm{C}=\mathrm{C})$; ${ }^{1} \mathrm{H}$ NMR (methanol- $\mathrm{d}_{6}, 500 \mathrm{MHz}$ )

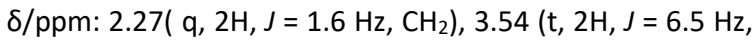
$\left.\mathrm{CH}_{2} \mathrm{X}\right), 4.68\left(\mathrm{t}, 2 \mathrm{H}, \mathrm{J}=6.4 \mathrm{~Hz}, \mathrm{OCH}_{2}\right), 7.01\left(\mathrm{~s}, 2 \mathrm{H}, \mathrm{H}_{2} \& \mathrm{H}_{6}\right) ;{ }^{13} \mathrm{C}$ NMR ( methanol-d $\mathrm{d}_{6}, 125 \mathrm{MHz}$ ) $\delta / \mathrm{ppm}: 29.12\left(\mathrm{C}_{9}\right), 31.86$ $\left(C_{10}\right), 63.39\left(C_{8}\right), 110.21\left(C_{2} \& C_{6}\right), 126.68\left(C_{1}\right), 139.84\left(C_{4}\right)$, $147.82\left(C_{3} \& C_{5}\right), 169.72\left(C_{7}\right) ;$ HR-ESI-MS: $m / z=292.21$ $[\mathrm{M}+\mathrm{H}]^{+}$.

\section{3-chloropropyl 3, 4, 5-trihydroxybenzoate (7c)}

IR (KBr) ũ/cm ${ }^{-1}: 3485(\mathrm{OH}), 3012\left(\mathrm{sp}^{2} \mathrm{CH}\right), 2905\left(\mathrm{sp}^{3} \mathrm{CH}\right)$, $1742(\mathrm{C}=\mathrm{O}), 1604,1499(\mathrm{C}=\mathrm{C})$; ${ }^{1} \mathrm{H}$ NMR ( methanol- $\mathrm{d}_{6}, 500$ $\mathrm{MHz}$ ) $\delta / p p m: 2.08\left(\mathrm{q}, 2 \mathrm{H}, J=6.3 \mathrm{~Hz}, \mathrm{CH}_{2}\right), 3.38(\mathrm{t}, 2 \mathrm{H}, J=$ $5.8 \mathrm{~Hz}, \mathrm{CH}_{2} \mathrm{X}$ ), $4.11\left(\mathrm{t}, 2 \mathrm{H}, J=6.4 \mathrm{~Hz}, \mathrm{OCH}_{2}\right), 6.81(\mathrm{~s}, 2 \mathrm{H}$, $\mathrm{H}_{2} \& \mathrm{H}_{6}$ ); ${ }^{13} \mathrm{C}$ NMR ( methanol- $\mathrm{d}_{6}, 125.0 \mathrm{MHz}$ ) $\delta / \mathrm{ppm}: 32.42$ $\left(C_{9}\right), 41.86\left(C_{10}\right), 62.39\left(C_{8}\right), 110.17\left(C_{2} \& C_{6}\right), 140.39\left(C_{4}\right)$, $125.64\left(C_{1}\right), 147.28\left(C_{3} \& C_{5}\right), 168.27\left(C_{7}\right)$; HR-ESI-MS: $m / z=$ $247.74[\mathrm{M}+\mathrm{H}]^{+}$.

\section{2,4-dinitrophenyl 3,4,5-trihydroxybenzoate (7d)}

IR (KBr) ṽ/cm-1: $3510(\mathrm{OH}), 1743$ (C=O), 1590 (C=C), 1510, 1335 (NO); ${ }^{1} \mathrm{H}$ NMR (methanol-d $6,500 \mathrm{MHz}$ ) $\delta / \mathrm{ppm}: 7.20$ $\left.\left(\mathrm{s}, 2 \mathrm{H}, \mathrm{H}_{2} \& \mathrm{H}_{6}\right), 7.71\left(\mathrm{~d}, 1 \mathrm{H}, J=8.5 \mathrm{~Hz}, \mathrm{H}_{6}\right)^{\prime}\right), 8.68(\mathrm{dd}, 1 \mathrm{H}, J=$ $\left.8.5 \mathrm{~Hz}, \mathrm{H}_{5^{\prime}}\right), 9.09\left(\mathrm{~d}, 1 \mathrm{H}, J=2.6 \mathrm{~Hz}, \mathrm{H}_{3^{\prime}}\right)^{1},{ }^{13} \mathrm{C}$ NMR (methanol$\left.\mathrm{d}_{6}, 125 \mathrm{MHz}\right)$ //ppm: $110.16\left(\mathrm{C}_{2} \& \mathrm{C}_{6}\right), 119.42\left(\mathrm{C}_{3^{\prime}}\right), 123.36$ $\left(C_{6^{\prime}}\right), 125.77\left(C_{1}\right), 127.91\left(C_{5^{\prime}}\right), 141.73\left(C_{4}\right), 143.18\left(C_{2^{\prime}}\right)$, $146.37\left(C_{4^{\prime}}\right), 148.95\left(C_{3} \& C_{5}\right), 154.87\left(C_{1^{\prime}}\right), 165.54\left(C_{7}\right)$; HRESI-MS: $m / z=337.21[\mathrm{M}+\mathrm{H}]^{+}$. 


\section{4-bromophenyl 3, 4, 5-trihydroxybenzoate (7e)}

IR (KBr) ṽ/cm ${ }^{-1}: 3492(\mathrm{OH}), 1743(\mathrm{C}=0), 1603,1490(\mathrm{C}=\mathrm{C})$, 1140 (CO); ${ }^{1} \mathrm{H}$ NMR (methanol- $\mathrm{d}_{6}, 500 \mathrm{MHz}$ ) $\delta / \mathrm{ppm}: 7.13$ $\left(\mathrm{s}, 2 \mathrm{H}, \mathrm{H}_{2} \& \mathrm{H}_{6}\right), 7.16\left(\mathrm{~d}, 2 \mathrm{H}, J=8.0 \mathrm{~Hz}, \mathrm{H}_{2^{\prime}} \& \mathrm{H}_{6^{\prime}}\right), 7.31(\mathrm{~d}, 2 \mathrm{H}$, $J=8.1 \mathrm{~Hz}, \mathrm{H}_{3^{\prime}} \& \mathrm{H}_{5^{\prime}}$ ); ${ }^{13} \mathrm{C}$ NMR (methanol- $\mathrm{d}_{6}, 125 \mathrm{MHz}$ )

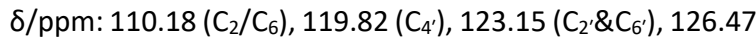
$\left(C_{1}\right), 130.32\left(C_{3^{\prime}} \& C_{5^{\prime}}\right), 141.49\left(C_{4}\right), 148.81\left(C_{3} \& C_{5}\right), 151.53$ $\left(\mathrm{C}_{1^{\prime}}\right), 160.75\left(\mathrm{C}_{7}\right)$; HR-ESI-MS: $m / z=326.21[\mathrm{M}+\mathrm{H}]^{+}$.

\section{2,4-dibromophenyl 3, 4, 5-trihydroxybenzoate (7f)} $\mathrm{IR}(\mathrm{KBr}) \tilde{u} / \mathrm{cm}^{-1}: 3490(\mathrm{OH}), 1740(\mathrm{C}=0), 1606,1495(\mathrm{C}=\mathrm{C})$, 1150 (CO); ${ }^{1} \mathrm{H}$ NMR (methanol- $\mathrm{d}_{6}, 500 \mathrm{MHz}$ ) $\delta / \mathrm{ppm}: 6.59$ (d, $\left.1 \mathrm{H}, J=8.0 \mathrm{~Hz}, \mathrm{H}_{6^{\prime}}\right), 7.15$ ( $\left.\mathrm{s}, 2 \mathrm{H}, \mathrm{H}_{2} \& \mathrm{H}_{6}\right), 7.56$ (dd, $1 \mathrm{H}, J=8.0$ $\left.\mathrm{Hz}, 1.5 \mathrm{~Hz}, \mathrm{H}_{5^{\prime}}\right), 7.75\left(\mathrm{~d}, 1 \mathrm{H}, J=2.3 \mathrm{~Hz}, \mathrm{H}_{3^{\prime}}\right) ;{ }^{13} \mathrm{C} N M R$ (methanol-d $\left.\mathrm{d}_{6}, 125 \mathrm{MHz}\right) \delta / \mathrm{ppm}: 108.32\left(\mathrm{C}_{2} \& \mathrm{C}_{6}\right), 124.67$ $\left(C_{4^{\prime}}\right), 126.81\left(C_{2^{\prime}}\right), 130.52\left(C_{5^{\prime}}\right), 133.78\left(C_{1}\right), 134.53\left(C_{6^{\prime}}\right)$, $135.24\left(C_{3^{\prime}}\right), 136.56\left(C_{1^{\prime}}\right), 140.39\left(C_{4}\right), 148.22\left(C_{3} \& C_{5}\right)$, $202.89\left(C_{7}\right)$; HR-ESI-MS: $m / z=405.21[\mathrm{M}+\mathrm{H}]^{+}$.

\section{Naphthalen-1-yl 3, 4, 5-trihydroxybenzoate (7g)}

IR (KBr) $\tilde{u} / \mathrm{cm}^{-1}: 3443$ (OH), 3040 (sp² CH), 1740 (C=O), 1598 (C=C), 1130 (CO); ${ }^{1} \mathrm{H}$ NMR (methanol- $\mathrm{d}_{6}, 500 \mathrm{MHz}$ ) $\delta / \mathrm{ppm}$ : $6.63\left(\mathrm{~d}, 1 \mathrm{H}, J=8.1 \mathrm{~Hz}, \mathrm{H}_{2^{\prime}}\right), 6.82\left(\mathrm{~s}, 2 \mathrm{H}, \mathrm{H}_{2} \& \mathrm{H}_{6}\right), 7.11-7.17$ $\left(\mathrm{m}, 2 \mathrm{H}, \mathrm{H}_{3^{\prime}} \& \mathrm{H}_{4^{\prime}}\right), 7.73\left(\mathrm{~d}, 1 \mathrm{H}, J=8.1 \mathrm{~Hz}, \mathrm{H}_{5^{\prime}}\right), 7.34-7.38(\mathrm{~m}$, $\left.2 \mathrm{H}, \mathrm{H}_{6^{\prime}} \& \mathrm{H}_{7^{\prime}}\right), 8.09\left(\mathrm{~d}, 1 \mathrm{H}, J=7.8 \mathrm{~Hz}, \mathrm{H}_{8^{\prime}}\right) ;{ }^{13} \mathrm{C} \mathrm{NMR}$

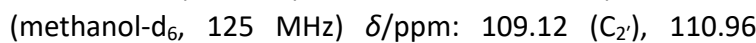
$\left(C_{2} / C_{6}\right), 121.12\left(C_{4^{\prime}}\right), 121.92\left(C_{8^{\prime}}\right), 124.17\left(C_{1}\right), 125.42\left(C_{7^{\prime}}\right)$, $126.12\left(C_{6^{\prime}}\right), 126.92\left(C_{3^{\prime}}\right), 127.91\left(C_{5^{\prime}}\right), 128.12\left(C_{9^{\prime}}\right), 134.72$ $\left(C_{10^{\prime}}\right), 141.21\left(C_{4}\right), 148.63\left(C_{3} / C_{5}\right), 152.81\left(C_{1^{\prime}}\right), 165.26\left(C_{7}\right)$; HR-ESI-MS: $m / z=297.31[\mathrm{M}+\mathrm{H}]^{+}$.

\section{2,6-dimethylphenyl 3, 4, 5-trihydroxybenzoate (7h)} IR (KBr) v//cm-1: $3510(\mathrm{OH}), 2910$ (sp $\left.{ }^{3} \mathrm{CH}\right), 1734$ (C=O), 1604 (C=C), ${ }^{1} \mathrm{H}$ NMR (methanol- $\mathrm{d}_{6}, 500 \mathrm{MHz}$ ) $\delta / \mathrm{ppm}: 2.36(\mathrm{~s}, 6 \mathrm{H}$, $\left.\mathrm{CH}_{3}\right), 6.54\left(\mathrm{~s}, 2 \mathrm{H}, \mathrm{H}_{2} \& \mathrm{H}_{6}\right), 6.99\left(\mathrm{t}, 1 \mathrm{H}, J=7.4 \mathrm{~Hz}_{2} \mathrm{H}_{4^{\prime}}\right), 7.20$ (d, $2 \mathrm{H}, J=7.4 \mathrm{~Hz}, \mathrm{H}_{3^{\prime}} \& \mathrm{H}_{5^{\prime}}$ ); ${ }^{13} \mathrm{C}$ NMR (methanol- $\mathrm{d}_{6}, 125 \mathrm{MHz}$ )

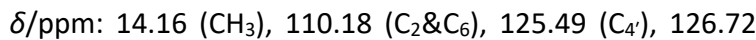
$\left(C_{1}\right), 127.89\left(C_{3^{\prime}} \& C_{5^{\prime}}\right), 132.51\left(C_{2^{\prime}} \& C_{6^{\prime}}\right), 141.28\left(C_{4}\right), 148.61$ $\left(C_{3} \& C_{5}\right) 150.11\left(C_{1^{\prime}}\right), 166.17\left(C_{7}\right)$; HR-ESI-MS: $m / z=275.29$ $[\mathrm{M}+\mathrm{H}]^{+}$.

\section{2,3,6-trimethylphenyl 3, 4, 5-trihydroxybenzoate (7i)} IR ( $\mathrm{KBr}) \tilde{u} / \mathrm{cm}^{-1}: 3480(\mathrm{C}=0), 2880\left(\mathrm{sp}^{3} \mathrm{CH}\right), 1740(\mathrm{C}=\mathrm{O})$, 1602, 1498 (C=C); ${ }^{1} \mathrm{H}$ NMR (methanol- $\mathrm{d}_{6}, 500 \mathrm{MHz}$ ) $\delta / \mathrm{ppm}$ : $2.18\left(\mathrm{~s}, 9 \mathrm{H}, \mathrm{CH}_{3}\right), 6.45\left(\mathrm{~s}, 2 \mathrm{H}, \mathrm{H}_{4^{\prime}} \& \mathrm{H}_{6^{\prime}}\right), 7.24\left(\mathrm{~s}, 2 \mathrm{H}, \mathrm{H}_{2} \& \mathrm{H}_{6}\right)$; ${ }^{13} \mathrm{C}$ NMR (methanol- $\mathrm{d}_{6}, 125.0 \mathrm{MHz}$ ) $\delta / \mathrm{ppm}: 12.37\left(3-\mathrm{CH}_{3}\right)$, $19.82\left(4-\mathrm{CH}_{3}\right), 24.69\left(6-\mathrm{CH}_{3}\right), 110.12\left(\mathrm{C}_{2} \& \mathrm{C}_{6}\right), 117.38\left(\mathrm{C}_{6}\right)$, $127.14\left(C_{2^{\prime}}\right), 128.18\left(C_{4^{\prime}}\right), 135.72\left(C_{5^{\prime}}\right), 137.99\left(C_{3^{\prime}}\right), 141.14$ $\left(C_{4}\right), 148.38\left(C_{3} \& C_{5}\right), 150.21\left(C_{1^{\prime}}\right), 166.14\left(C_{7}\right)$; HR-ESI-MS: $m / z=289.32[\mathrm{M}+\mathrm{H}]^{+}$.

\section{1-hydroxybenzotriazyl 3, 4, 5-trihydroxybenzoate (7j)} IR (KBr) $\tilde{u} / \mathrm{cm}^{-1}: 3510(\mathrm{C}=\mathrm{O}), 3020\left(\mathrm{sp}^{2} \mathrm{CH}\right), 1730(\mathrm{C}=\mathrm{O})$,
1604, 1494 (C=C), 1233 (CO); ${ }^{1} \mathrm{H}$ NMR (methanol-d $\mathrm{d}_{6}, 500$ $\mathrm{MHz}$ ) $\delta / p p m: 6.55\left(\mathrm{~s}, 2 \mathrm{H}, \mathrm{H}_{2} \& \mathrm{H}_{6}\right), 6.87(\mathrm{t}, 2 \mathrm{H}, J=7.4 \mathrm{~Hz}$, $\left.\mathrm{H}_{5^{\prime}} \& \mathrm{H}_{6^{\prime}}\right), 7.17\left(\mathrm{~d}, 2 \mathrm{H}, J=7.7 \mathrm{~Hz}, \mathrm{H}_{4^{\prime}} \& \mathrm{H}_{7^{\prime}}\right) ;{ }^{13} \mathrm{C} \mathrm{NMR}$

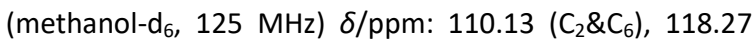
$\left(\mathrm{C}_{4^{\prime}} \& \mathrm{C}_{7^{\prime}}\right), 126.54\left(\mathrm{C}_{1}\right), 127.98\left(\mathrm{C}_{5^{\prime}} \& \mathrm{C}_{6^{\prime}}\right), 134.83\left(\mathrm{C}_{3 \mathrm{a}}\right), 141.16$ $\left(C_{4}\right), 144.58\left(C_{7 a}\right), 147.27\left(C_{3} \& C_{5}\right), 165.91\left(C_{7}\right) ;$ HR-ESI-MS: $m / z=288.26[\mathrm{M}+\mathrm{H}]^{+}$.

\section{2-methyl-8-quinolinyl 3, 4, 5-trihydroxybenzoate (7k)} IR (KBr) $\tilde{u} / \mathrm{cm}^{-1}: 3502(\mathrm{OH}), 3040\left(\mathrm{sp}^{2} \mathrm{CH}\right), 1745(\mathrm{C}=\mathrm{O})$, 1601, $1499(\mathrm{C}=\mathrm{C}) ;{ }^{1} \mathrm{H}$ NMR (methanol- $\mathrm{d}_{6}, 500 \mathrm{MHz}$ ) $\delta / \mathrm{ppm}$ : $2.61\left(\mathrm{~s}, 3 \mathrm{H}, \mathrm{CH}_{3}\right), 6.62\left(\mathrm{~d}, 1 \mathrm{H}, J=9.0 \mathrm{~Hz}, \mathrm{H}_{7^{\prime}}\right), 6.71(\mathrm{~s}, 2 \mathrm{H}$, $\left.\mathrm{H}_{2} \& \mathrm{H}_{6}\right), 7.10\left(\mathrm{~d}, 1 \mathrm{H}, J=7.6 \mathrm{~Hz}, \mathrm{H}_{3^{\prime}}\right), 7.21(\mathrm{t}, 1 \mathrm{H}, J=7.0 \mathrm{~Hz}$, $\left.\mathrm{H}_{6^{\prime}}\right), 7.33\left(\mathrm{~d}, 1 \mathrm{H}, J=7.9 \mathrm{~Hz}, \mathrm{H}_{5^{\prime}}\right), 7.79\left(\mathrm{~d}, 1 \mathrm{H}, J=8.3 \mathrm{~Hz}, \mathrm{H}_{4^{\prime}}\right)$; ${ }^{13} \mathrm{C}$ NMR (methanol- $\left.\mathrm{d}_{6}, 125.0 \mathrm{MHz}\right) \delta / \mathrm{ppm}$ : $25.67\left(\mathrm{CH}_{3}\right)$, $110.82\left(C_{2} \& C_{6}\right), 113.26\left(C_{7^{\prime}}\right), 120.21\left(C_{5^{\prime}}\right), 122.35\left(C_{3^{\prime}}\right)$, $125.48\left(C_{1}\right), 125.82\left(C_{6^{\prime}}\right), 127.58\left(C_{10^{\prime}}\right), 134.83\left(C_{4^{\prime}}\right), 138.22$ $\left(C_{9^{\prime}}\right), 141.52\left(C_{4}\right), 148.19\left(C_{3} \& C_{5}\right), 152.54\left(C_{8^{\prime}}\right), 160.15\left(C_{2^{\prime}}\right)$, $166.45\left(\mathrm{C}_{7}\right)$; HR-ESI-MS: $m / z=312.39[\mathrm{M}+\mathrm{H}]^{+}$.

\section{2-methoxy-4-methylphenyl 3,4,5-trihydroxybenzoate (7)} IR (KBr) $\tilde{u} / \mathrm{cm}^{-1}: 3498(\mathrm{OH}), 2920\left(\mathrm{sp}^{3} \mathrm{CH}\right), 1741(\mathrm{C}=\mathrm{O})$, 1610, $1503(\mathrm{C}=\mathrm{C}) ;{ }^{1} \mathrm{H}$ NMR (methanol- $\mathrm{d}_{6}, 500 \mathrm{MHz}$ ) $\delta / \mathrm{ppm}$ : $2.20\left(\mathrm{~s}, 3 \mathrm{H}, \mathrm{CH}_{3}\right), 3.62\left(\mathrm{~s}, 3 \mathrm{H}, \mathrm{OCH}_{3}\right), 6.62(\mathrm{~d}, 1 \mathrm{H}, J=7.9 \mathrm{~Hz}$, $\left.\mathrm{H}_{5^{\prime}}\right), 6.75\left(\mathrm{~s}, 1 \mathrm{H}, \mathrm{H}_{3^{\prime}}\right), 6.80\left(\mathrm{~d}, 1 \mathrm{H}, J=8.0 \mathrm{~Hz}, \mathrm{H}_{6^{\prime}}\right), 7.07(\mathrm{~s}, 2 \mathrm{H}$, $\mathrm{H}_{2} \& \mathrm{H}_{6}$ ); ${ }^{13} \mathrm{C}$ NMR (methanol- $\mathrm{d}_{6}, 125.0 \mathrm{MHz}$ ) $\delta / \mathrm{ppm}: 23.43$ $\left(\mathrm{CH}_{3}\right), 56.08\left(\mathrm{OCH}_{3}\right), 110.46\left(\mathrm{C}_{2} \& \mathrm{C}_{6}\right), 113.76\left(\mathrm{C}_{3^{\prime}}\right), 121.81$ $\left(C_{5^{\prime}}\right), 123.18\left(C_{6^{\prime}}\right), 126.13\left(C_{1}\right), 135.85\left(C_{1^{\prime}}\right), 137.72\left(C_{4^{\prime}}\right)$, $139.42\left(C_{4}\right), 148.10\left(C_{3} \& C_{5}\right), 156.66\left(C_{2^{\prime}}\right), 166.74\left(C_{7}\right)$; HRESI-MS: $m / z=291.08[\mathrm{M}+\mathrm{H}]^{+}$.

\section{3-phenylphenyl 3, 4, 5-trihydroxybenzoate (7m)}

IR (KBr) $\tilde{u} / \mathrm{cm}^{-1}: 3510(\mathrm{OH}), 3041\left(\mathrm{sp}^{3} \mathrm{CH}\right), 1742(\mathrm{C}=\mathrm{O})$, 1599, 1490 (C=C); ${ }^{1} \mathrm{H}$ NMR (methanol- $\mathrm{d}_{6}, 500 \mathrm{MHz}$ ) $\delta / \mathrm{ppm}$ : $6.58\left(\mathrm{~s}, 2 \mathrm{H}, \mathrm{H}_{2} \& \mathrm{H}_{6}\right), 7.15\left(\mathrm{~d}, 1 \mathrm{H}, J=7.5 \mathrm{~Hz}, \mathrm{H}_{4^{\prime}}\right), 7.24(\mathrm{~s}, 1 \mathrm{H}$, $\left.\mathrm{H}_{2^{\prime}}\right), 7.35\left(\mathrm{t}, 1 \mathrm{H}, J=6.9 \mathrm{~Hz}, \mathrm{H}_{4^{\prime \prime}}\right), 7.56-7.40(\mathrm{~m}, 4 \mathrm{H}, \mathrm{ArH}), 7.63$ (d, $2 \mathrm{H}, J=7.1 \mathrm{~Hz}, \mathrm{H}_{2^{\prime \prime}} \& \mathrm{H}_{6^{\prime \prime}}$ ); ${ }^{13} \mathrm{C}$ NMR (methanol-d $\mathrm{d}_{6}, 125$

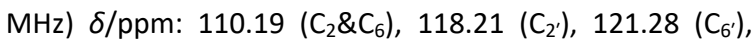
$125.16\left(C_{4^{\prime}}\right), 127.59\left(C_{2^{\prime \prime}} \& C_{6^{\prime \prime}}\right), 127.59\left(C_{4^{\prime \prime}}\right), 128.82\left(C_{1}\right)$, $129.54\left(C_{3^{\prime \prime}} \& C_{5^{\prime \prime}}\right), 130.58\left(C_{5}\right), 136.32\left(C_{1^{\prime \prime}}\right), 137.29\left(C_{3^{\prime}}\right)$, $141.14\left(C_{4}\right), 148.23\left(C_{3} \& C_{5}\right), 151.97\left(C_{1^{\prime}}\right), 166.31\left(C_{7}\right)$; HRESI-MS: $m / z=323.38[\mathrm{M}+\mathrm{H}]^{+}$.

\section{2-isopropoxyphenyl 3, 4, 5-trihydroxybenzoate (7n)} IR $(\mathrm{KBr}) \tilde{u} / \mathrm{cm}^{-1}: 3505(\mathrm{OH}), 3040\left(\mathrm{sp}^{2} \mathrm{CH}\right), 1739(\mathrm{C}=\mathrm{O})$, 1604, 1501 (C=C), 1109 (CO); ${ }^{1} \mathrm{H}$ NMR (methanol-d 6,500 $\mathrm{MHz}) \delta / \mathrm{ppm}: 1.24\left(\mathrm{~d}, 6 \mathrm{H}, J=6.0 \mathrm{~Hz}, \mathrm{CH}_{3}\right), 4.57-4.51(\mathrm{~m}, 1 \mathrm{H}$, $\mathrm{CH}), 6.59\left(\mathrm{~s}, 2 \mathrm{H}, \mathrm{H}_{2} \& \mathrm{H}_{6}\right), 6.98\left(\mathrm{t}, 1 \mathrm{H}, J=7.5 \mathrm{~Hz}, \mathrm{H}_{5^{\prime}}\right)$, 7.12-7.03 (m, $\left.\mathrm{H}_{4^{\prime}} \& \mathrm{H}_{6^{\prime}}\right), 7.20\left(\mathrm{~d}, 1 \mathrm{H}, J=6.2 \mathrm{~Hz}, \mathrm{H}_{3^{\prime}}\right) ;{ }^{13} \mathrm{C} \mathrm{NMR}$ ( methanol-d $\mathrm{d}_{6}, 125.0 \mathrm{MHz}$ ) $\delta / \mathrm{ppm}: 23.13\left(\mathrm{CH}_{3}\right), 26.46$ $\left(\mathrm{CH}_{3}\right), 110.14\left(\mathrm{C}_{2} \& \mathrm{C}_{6}\right), 121.35\left(\mathrm{C}_{6^{\prime}}\right), 122.51\left(\mathrm{C}_{4^{\prime}}\right), 126.69$ $\left(C_{3^{\prime}} \& C_{5^{\prime}}\right), 141.53\left(C_{4}\right), 143.71\left(C_{2^{\prime}}\right), 147.45\left(C_{1^{\prime}}\right), 148.62$ $\left(C_{3} \& C_{5}\right), 165.53\left(C_{7}\right)$; HR-ESI-MS: $m / z=305.19[\mathrm{M}+\mathrm{H}]^{+}$. 
3-methoxyphenyl 3, 4, 5-trihydroxybenzoate (7o) IR (KBr) $\tilde{u} / \mathrm{cm}^{-1}: 3540(\mathrm{OH}), 1743(\mathrm{C}=0), 1610,1503(\mathrm{C}=\mathrm{C})$, 1250 (CO), ${ }^{1} \mathrm{H}$ NMR (methanol- $\mathrm{d}_{6}, 500 \mathrm{MHz}$ ) $\delta / \mathrm{ppm}: 3.80$ $\left(\mathrm{s}, 3 \mathrm{H}, \mathrm{OCH}_{3}\right), 6.47\left(\mathrm{dd}, 1 \mathrm{H}, J=4.5 \mathrm{~Hz}, 2.3 \mathrm{~Hz}, \mathrm{H}_{2^{\prime}}\right), 6.56-6.51$ ( $\left.\mathrm{m}, 1 \mathrm{H}, \mathrm{H}_{4^{\prime}}\right), 6.98\left(\mathrm{~s}, 2 \mathrm{H}, \mathrm{H}_{2} \& \mathrm{H}_{6}\right), 7.02\left(\mathrm{t}, 1 \mathrm{H}, J=8.5 \mathrm{~Hz}, \mathrm{H}_{5^{\prime}}\right.$ ); ${ }^{13} \mathrm{C}$ NMR (methanol- $\mathrm{d}_{6}, 125 \mathrm{MHz}$ ) $\delta / \mathrm{ppm}: 44.82\left(\mathrm{CH}_{2}\right)$, $55.48\left(\mathrm{CH}_{3}\right), 108.61\left(\mathrm{C}_{2} \& \mathrm{C}_{6}\right), 113.37\left(\mathrm{C}_{4^{\prime}}\right), 114.33\left(\mathrm{C}_{2^{\prime}}\right)$ $123.58\left(C_{6^{\prime}}\right), 130.23\left(C_{5^{\prime}}\right), 132.21\left(C_{1}\right), 136.78\left(C_{1^{\prime}}\right), 141.24$ $\left(C_{4}\right), 149.83\left(C_{3} \& C_{5}\right), 160.17\left(C_{3^{\prime}}\right), 201.74\left(C_{7}\right)$; HR-ESI-MS: $m / z=277.16[\mathrm{M}+\mathrm{H}]^{+}$.

\section{Antimicrobial Activity}

\section{Microbial Strains}

Samples were tested individually against all the microorganisms obtained from microbial collection of PCSIR antimicrobial laboratory Lahore and were maintained on Mueller-Hinton (MHA) and potato dextrose (PDA) agar slants at $4{ }^{\circ} \mathrm{C}$.

\section{Preparation of Media}

Clear solutions of MHA and PDA were prepared by dissolving required quantities in deionized water and heating in conical flasks. Mueller-Hinton broth (MHB) and Sobouraud dextrose broth (SDB) solutions were prepared in deionized water in test tubes. All the media flasks and test tubes were plugged with cotton wool and sterilized in an autoclave for 15 minutes at $121{ }^{\circ} \mathrm{C}$. To avoid contamination, sterilized agar medium $(20.0 \mathrm{ml})$ was poured aseptically into sterilized petri dishes. On solidification, they were incubated for $24 \mathrm{~h}$ at $37^{\circ} \mathrm{C}$ in an inverted position to avoid evaporation of water from medium within the plates. Uncontaminated MHA and PDA plates were used for culturing bacteria and fungi.

\section{Preparation of Inoculum}

Bacterial strains were cultured from stock slants (kept at 4 ${ }^{\circ} \mathrm{C}$ ) in MHB for 24 hat $37^{\circ} \mathrm{C}$. Inoculum of each strain was prepared by diluting the active and pure culture with deionized water until it achieved the turbidity of the 0.5 McFarland barium standard. Test fungi strains were cultured on PDA for $3-5$ days at $30{ }^{\circ} \mathrm{C}$ to induce spore formation. Turbidity was adjusted to the $0.5 \mathrm{McFarland}$ barium standard by diluting with deionized water.

\section{Agar Well-diffusion Protocol[23]}

Autoclaved MHA plates were seeded onto the surface with 24 hour old broth culture of different bacteria. Samples were dissolved thoroughly in DMSO and different concentrations were prepared by serial dilution method. Four wells of $8.0 \mathrm{~mm}$ were cut out in each plate using sterile cork borer. Plant extracts of different concentrations (60.0 $\mu \mathrm{L}$ ) were added carefully in each plate and were incubated for $24 \mathrm{~h}$ at $37^{\circ} \mathrm{C}$. Ciprofloxacin (standard antibiotic) was used as positive control, while DMSO served as negative control.

For antifungal activity, diluted solution of fungi was swabbed onto the entire surface of PDA plates. The inoculated plates were dried, followed by carving four wells on each plate by sterilized cork borer. Different concentrations of each sample $(60.0 \mu \mathrm{L})$ were poured carefully in plates by sterilized micropipettes and were incubated for $48 \mathrm{~h}$ at $30^{\circ} \mathrm{C}$. Reference drug was nystatin while DMSO served as negative control. Three plates were inoculated for each microbe. Antimicrobial potential was estimated from diameter of clear zone around each well.

\section{Minimum Inhibitory Concentration (MIC) and Minimum Mactericidal/Fungicidal Concentration Protocol[24,25]}

A $24 \mathrm{~h}$ bacterial culture in MHB and Tween $80(0.5 \% \mathrm{v} / \mathrm{v})$ was diluted 1000X. Sample solution $(0.3 \mathrm{ml})$ was added to diluted culture $(2.7 \mathrm{ml})$ and bacterium growth was assessed from turbidity after $24 \mathrm{~h}$ incubation at $37{ }^{\circ} \mathrm{C}$. Fungi was cultured for $2-3$ days at $30^{\circ} \mathrm{C}$ in SDB with Tween $80(0.5 \%$ $v / v)$. 1000X diluted culture $(2.7 \mathrm{ml})$ was added to test sample solution $(0.3 \mathrm{ml})$ and incubated for $48 \mathrm{~h}$ at $30^{\circ} \mathrm{C}$ to check the appearance of turbidity. MIC was taken as that conc. of the sample where no turbidity appears in the culture medium. For estimation of MBC/MFC an aliquot of each tube where no microbial growth was observed in prior test was swabbed on MHA plates in case of bacteria and on PDA plates in case of fungal strains thoroughly and incubated under previously described growth conditions. The lowest concentration that retarded bacterial/fungal growth was recorded as MBC/MFC.

\section{Antioxidant Activity}

\section{DPPH Scavenging Assay}

DPPH radical-quenching ability of samples was evaluated by applying previously reported. ${ }^{[26]}$

\section{ABTSDecolorization Assay}

$\mathrm{ABTS}^{+}$decolorization potential was evaluated by applying previously reported method. ${ }^{[26]}$

\section{Anti-lipid Peroxidation Assay}

Anti-lipid peroxidation activity of samplesand reference standards was assessedby applying previously reported method. [26]

\section{RESULTS AND DISCUSSION}

\section{Chemistry}

The synthetic route for the preparation of GA esters is presented in Scheme 1. To afford compounds 7a-7o, GA (1) was first esterified as propyl ester (2) to avoid side reactions. Protection of phenolic moiety was accomplished 
<smiles>O=C(O)c1cc(O)c(O)c(O)c1</smiles>

1

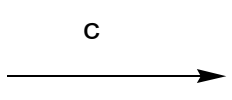<smiles>[R]OC(=O)c1cc(OCc2ccccc2)c(OCc2ccccc2)c(OCc2ccccc2)c1</smiles><smiles>CCOC(=O)c1cc(O)c(O)c(I)c1</smiles>

2<smiles>C#C</smiles>

4

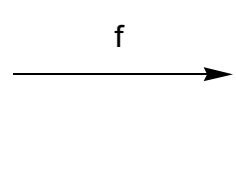<smiles>CCOC(=O)c1cc(CCc2ccccc2)c(OCc2ccccc2)c(OCC)c1</smiles>

3<smiles>O=C(Cl)c1cc(OCc2ccccc2)c(OCc2ccccc2)c(OCc2ccccc2)c1</smiles>

5

Scheme 1. Synthetic route of novel gallic acid derivatives 7a-7o, Reagents and conditions: (a) $\mathrm{SOCl}_{2}, \mathrm{CH}_{3} \mathrm{CH}_{2} \mathrm{CH}_{2} \mathrm{OH}, 70{ }^{\circ} \mathrm{C}$, reflux $6 \mathrm{~h}$; (b) $\mathrm{C}_{6} \mathrm{H}_{5} \mathrm{CH}_{2} \mathrm{Cl}, \mathrm{K}_{2} \mathrm{CO}_{3}$, DMF, reflux 4 h; (c) $\mathrm{CH}_{3} \mathrm{OH}, \mathrm{NaOH}$, reflux $4 \mathrm{~h}$; (d) $\mathrm{SOCl}_{2}, \mathrm{C}_{5} \mathrm{H}_{5} \mathrm{~N}, \mathrm{C}_{6} \mathrm{H}_{6}$, reflux 3 h; (e) ROH (Table 1), $\mathrm{Et}_{3} \mathrm{~N}, \mathrm{CHCl}_{3}$, reflux 2-16 h; (f) Pd/C, $\mathrm{H}_{2}$ (Atm), $\mathrm{CHCl}_{3}, \mathrm{CH}_{3} \mathrm{OH}, \mathrm{RT}$ for $10 \mathrm{~h}$.

by benzyl chloride in DMF to produce propyl 3, 4, 5tribenzyloxy benzoate (3) with $73 \%$ yield prior to activation as acid chloride. Later, saponification using $\mathrm{NaOH}$ in methanol and water was employed to get 3,4,5tribenzyloxy benzoate (4). Intermediate acid chloride (5) was obtained by treating with thionyl chloride, followed by esterification in the presence of $\mathrm{Et}_{3} \mathrm{~N}$ in dry anhydrous chloroform under refluxing condition to give corresponding benzylated esters (6a-6o). Deprotectionusing palladium/charcoal activated in hydrogen atmosphere at room temperature afforded compounds 7a-7o. We obtained fifteen gallic acid derivatives that together with gallic acid were subjected to in vitro assessment of antimicrobial potential against an array of microbes. Electron transfer (ET) and hydrogen atom transfer (HAT) antioxidant assays were employed to evaluate antioxidant potential of the synthesized compounds.

\section{Antimicrobial Activity}

The antimicrobial activity of synthesized novel gallic acid derivatives was assessed qualitatively and quantitatively in vitro by measuring zone of inhibition and $\mathrm{MIC}$ and $\mathrm{MBC}$ values. For this purpose three gram-positive bacteriaBacillus subtilis (ATCC 6633), Staphylococcus aureus (ATCC 25923) , Bacillus licheniformis (PCSIR-B-252); five gramnegative bacteria-Pseudomonas aeruginosa (ATCC 27853), Eschrecia coli (ATCC 25922), Pseudomonas aeruginosa (ATCC 27853), Salmonella typhimurium (ATCC 14028), Enterobacter aerogenes (ATCC 13043), Proteus mirabilis (ATCC 29245), and two fungal strains- Candida albicans (ATCC 10239) and Aspergillus niger (PCSIR-M-204) were employed using well-diffusion method and results are represented in the Table 2 along with reference drugs i.e. ciprofloxacin and nystatin as positive control. Initially, lead compound gallic acid and derivatives $\mathbf{7 a - 7 0}$ were screened at four different concentrations 2.0, 1.0, 0.5, $0.25 \mathrm{mg} \mathrm{mL}^{-1}$ per well for qualitative assessment of antimicrobial and antifungal potency. Zone of inhibition presented in Table 1 indicated that microbes exhibited variable sensitivity towards tested compounds, though most of the derivatives were more effective against gram-positive pathogens in comparison to gram-negative ones. The two tested fungal 
Table 1. Physical and chemical data of derivatives 7a-7o

\begin{tabular}{|c|c|c|c|c|c|c|c|}
\hline Compound & $R$ & M.P. $/{ }^{\circ} \mathrm{C}$ & $\begin{array}{c}\% \\
\text { Yield }\end{array}$ & Compound & $R$ & M.P. $/{ }^{\circ} \mathrm{C}$ & $\begin{array}{c}\% \\
\text { Yield }\end{array}$ \\
\hline $7 a$ & & $156-158$ & 65 & $7 i$ & & $162-164$ & 58 \\
\hline $7 b$ & & $153-155$ & 67 & 7j & & 198-199 & 72 \\
\hline $7 c$ & & $157-158$ & 70 & $7 k$ & & $183-185$ & 76 \\
\hline $7 d$ & & $165-167$ & 45 & 71 & & $133-135$ & 77 \\
\hline $7 e$ & & $132-133$ & 64 & $7 m$ & & $148-151$ & 69 \\
\hline $7 f$ & & $139-131$ & 58 & $7 n$ & & $124-125$ & 68 \\
\hline $7 g$ & & 117-119 & 58 & 70 & & $126-127$ & 72 \\
\hline $7 \mathrm{~h}$ & & $178-180$ & 42 & & & & \\
\hline
\end{tabular}

$\mathrm{R}$ is the alkyl part of the coupling alcohols.

strains were least susceptible to the synthesized derivatives nevertheless they were immune towards gallic acid and did not exhibit antifungal potential under the test conditions. In general compounds were more effective against $A$. niger than $C$. albicans. Activities obtained through well diffusion method were confirmed by evaluating MIC and MBC values.

Table 3 represents the MIC (minimal inhibitory concentration) of the synthesized derivatives. It is the lowest concentration of antimicrobial agent that could visibly inhibits microbial growth without giving any indication whether mode of action was bacteriostatic or bactericidal. Tested compounds exhibited better inhibition of bacteria than fungal strains. It is clear that compounds 7a and 7c showed highest antimicrobial potency with MICs $0.015 \mathrm{mg} \mathrm{mL}^{-1}$ and $0.031 \mathrm{mg} \mathrm{mL}^{-1}$ for tested gram positive microbes as compared to lead i.e. upto 16 and 8 fold more potent than parent. In general inhibition was one fold lower for $S$. aureus than B. subtilis and B. licheniformis. According to MIC data obtained it was observed that majority of the compounds inhibited all the listed microbes modestly with some exceptions for instance, 7l showed potent antimicrobial action against $B$. subtilis with lowest MIC value of $0.015 \mathrm{mg} \mathrm{mL}^{-1}$ that could be an interesting starting 
Table 2. Zone of inhibition $(\mathrm{mm})$ of the compounds $7 \mathrm{a}-70$

\begin{tabular}{|c|c|c|c|c|c|c|c|c|c|c|}
\hline \multirow{2}{*}{ Compounds } & \multicolumn{3}{|c|}{ Gram-positive bacteria } & \multicolumn{5}{|c|}{ Gram-negative bacteria } & \multicolumn{2}{|c|}{ Fungi } \\
\hline & a & $b$ & c & $d$ & e & $f$ & g & h & i & j \\
\hline 1 & $9.33 \pm 0.3^{(a)}$ & $9.66 \pm 0.3$ & $11.1 \pm 0.7$ & - & - & - & - & - & NA & NA \\
\hline $7 a$ & $13.8 \pm 0.4$ & $13.5 \pm 0.7$ & $11.4 \pm 0.2$ & $9.33 \pm 0.2$ & $14.2 \pm 0.4$ & $9.66 \pm 0.3$ & $13.1 \pm 0.3$ & $12.3 \pm 0.6$ & - & - \\
\hline $7 b$ & $11.3 \pm 0.3$ & $9.66 \pm 0.2$ & $10.7 \pm 0.5$ & $9.33 \pm 0.3$ & $12.4 \pm 0.3$ & $10.3 \pm 0.6$ & $9.33 \pm 0.6$ & $12.5 \pm 0.7$ & - & - \\
\hline $7 c$ & $13.5 \pm 0.4$ & $14.5 \pm 0.3$ & $11.8 \pm 0.3$ & $12.3 \pm 0.6$ & $13.5 \pm 0.6$ & $10.6 \pm 0.7$ & $14.1 \pm 0.3$ & $13.5 \pm 0.4$ & - & - \\
\hline $7 d$ & $13.4 \pm 0.3$ & $14.6 \pm 0.5$ & $15.2 \pm 0.2$ & $9.33 \pm 0.1$ & $13.4 \pm 0.4$ & $10.4 \pm 0.2$ & $12.3 \pm 0.3$ & $13.4 \pm 0.6$ & $11.4 \pm 0.5$ & $10.4 \pm 0.5$ \\
\hline $7 e$ & $11.7 \pm 0.5$ & $14.3 \pm 0.3$ & $13.3 \pm 0.2$ & $10.2 \pm 0.5$ & $15.2 \pm 0.6$ & $10.9 \pm 0.3$ & $13.3 \pm 1.0$ & $13.1 \pm 1.2$ & - & - \\
\hline $7 f$ & $16.8 \pm 1.1$ & $13.6 \pm 0.2$ & $15.2 \pm 0.6$ & $10.2 \pm 0.7$ & $15.5 \pm 0.2$ & $9.33 \pm 0.3$ & $13.2 \pm 0.4$ & $11.3 \pm 0.5$ & - & - \\
\hline $7 \mathrm{~g}$ & $10.5 \pm 0.4$ & $9.33 \pm 0.3$ & $14.6 \pm 0.4$ & $10.1 \pm 0.6$ & $11.3 \pm 0.6$ & NA & $10.2 \pm 0.5$ & $11.5 \pm 0.2$ & - & - \\
\hline $7 \mathrm{~h}$ & $10.4 \pm 0.5$ & $13.1 \pm 0.2$ & $12.3 \pm 0.5$ & - & $12.4 \pm 0.6$ & $9.66 \pm 1.3$ & $12.2 \pm 1.3$ & $10.1 \pm 1.0$ & - & - \\
\hline $7 i$ & $10.3 \pm 0.8$ & $13.5 \pm 1.4$ & $13.4 \pm 0.4$ & - & $14.7 \pm 0.3$ & - & $12.1 \pm 1.4$ & $11.4 \pm 0.5$ & - & - \\
\hline $7 \mathrm{j}$ & $15.4 \pm 0.6$ & $14.4 \pm 0.4$ & $12.4 \pm 0.5$ & $9.33 \pm 0.1$ & $14.1 \pm 0.6$ & $11.2 \pm 0.5$ & $12.2 \pm 0.7$ & $14.5 \pm 0.2$ & - & - \\
\hline $7 k$ & $14.3 \pm 0.3$ & $13.7 \pm 0.2$ & $12.4 \pm 0.6$ & $10.3 \pm 0.4$ & $13.1 \pm 0.3$ & - & $13.1 \pm 0.7$ & $13.2 \pm 0.4$ & - & - \\
\hline 71 & $11.5 \pm 0.4$ & $13.4 \pm 0.3$ & $12.4 \pm 1.1$ & - & $10.2 \pm 0.3$ & $9.33 \pm 0.5$ & $10.4 \pm 0.4$ & $11.2 \pm 0.4$ & - & - \\
\hline $7 m$ & $9.33 \pm 0.5$ & $12.4 \pm 0.4$ & $13.2 \pm 0.1$ & - & $10.3 \pm 0.3$ & - & NA & $9.33 \pm 0.3$ & - & - \\
\hline $7 n$ & $14.3 \pm 0.2$ & $14.4 \pm 0.5$ & $15.4 \pm 0.5$ & - & $12.3 \pm 0.7$ & - & $11.3 \pm 0.5$ & $11.6 \pm 0.7$ & - & - \\
\hline 70 & $13.1 \pm 0.3$ & $13.3 \pm 0.6$ & $13.5 \pm 0.6$ & - & $11.4 \pm 0.4$ & - & $9.33 \pm 0.4$ & $9.33 \pm 0.2$ & - & - \\
\hline Ciprofloxacin & $32.3 \pm 0.3$ & $29.6 \pm 0.1$ & $31.3 \pm 0.4$ & $26.4 \pm 0.3$ & $24.5 \pm 0.3$ & $22.8 \pm 0.4$ & $33.8 \pm 0.8$ & $35.4 \pm 0.6$ & & \\
\hline
\end{tabular}

Nystatin

DMSO

(a) Diameter of inhibition zone includes the diameter of well $(8.0 \mathrm{~mm})$; -: absence of measurable inhibition;NA: not active; \pm : Standard Deviation; a: B. subtilis;

b: S. aureus; c: B. licheniformis; d: P. aeruginosa; e: E. coli; f: P. mirabilis; g: S. typhimurium; h: E. aerogenes; i: C. albicans; j: A.niger.

point in the pursuit of specific antimicrobial agent targeting B. subtilis.

Antimicrobial tests carried out against gram negative bacteria showed that in general they were much resistant against synthesized compounds, though diversity in MICs was obtained as shown in Table 3. Compound 7c emerged as most potent agent against all the tested gram-negative microbes except $P$. aeruginosa with MICs $0.015 \mathrm{mg} \mathrm{mL}^{-1}$. $P$. mirabilis was found to be least susceptible as a much higher MICs were observed against it and almost all the compounds except 7c exhibited weak inhibitory profile. Whereas $E$. coli was found to be most susceptible gramnegative bacteria among the tested microbes. In general, synthesized compounds appear to be more active against gram positive strains while gram negative bacteria showed resistance with higher MICs.
Unfortunately most of the synthesized compounds were least effective against tested fungi (Table 3 ) with very high MICs in the range of $0.5-2.0 \mathrm{mg} \mathrm{mL}^{-1}$.Gallic acid did not show activity against the tested fungal strains that is in accordance with the previous reports. ${ }^{[27]}$ In comparison to lead, introduction of different moieties remodeled behavior of the derivatives and they elicited antifungal response though no significant activity was observed.

Figure 1 shows the correlation between MICs of synthesized compounds against different sets of microbes as represented by plotmatrix graphs in a view to evaluate their pattern of activity. In the figure, rows represent plotmatrices for MICs, whereas the columns represent gram-positive, gram-negative and fungal strains respectively. The scatter plot in each image presents the correlation between the MICs of two microbes. Pearson 
Table 3. MIC (MBC) mg mL $\mathrm{m}^{-1}$ of the compounds $7 \mathrm{a}-70$

\begin{tabular}{|c|c|c|c|c|c|c|c|c|c|c|}
\hline \multirow{2}{*}{ Compounds } & \multicolumn{3}{|c|}{ Gram-positive Microbes } & \multicolumn{5}{|c|}{ Gram-negative Microbes } & \multicolumn{2}{|c|}{ Fungi } \\
\hline & a & $b$ & c & $d$ & e & f & g & $\mathrm{h}$ & i & j \\
\hline 1 & $\begin{array}{l}0.25 \\
(0.5)\end{array}$ & $\begin{array}{l}0.25 \\
(1.0)\end{array}$ & $\begin{array}{l}0.25 \\
(0.5)\end{array}$ & $\begin{array}{c}1.0 \\
(2.0)\end{array}$ & $\begin{array}{c}1.0 \\
(>2.0)\end{array}$ & $\begin{array}{c}2.0 \\
(>2.0)\end{array}$ & $\begin{array}{c}0.5 \\
(1.0)\end{array}$ & $\begin{array}{c}1.0 \\
(>2.0)\end{array}$ & NA & NA \\
\hline $7 a$ & $\begin{array}{c}0.031 \\
(0.031)\end{array}$ & $\begin{array}{c}0.015 \\
(0.031)\end{array}$ & $\begin{array}{c}0.031 \\
(0.062)\end{array}$ & $\begin{array}{c}0.12 \\
(0.25)\end{array}$ & $\begin{array}{c}0.015 \\
(0.031)\end{array}$ & $\begin{array}{c}0.12 \\
(0.25)\end{array}$ & $\begin{array}{l}0.031 \\
(0.12)\end{array}$ & $\begin{array}{c}0.031 \\
(0.062)\end{array}$ & $\begin{array}{c}2.0 \\
(>2.0)\end{array}$ & $\begin{array}{c}1.0 \\
(>2.0)\end{array}$ \\
\hline $7 b$ & $\begin{array}{l}0.062 \\
(0.25)\end{array}$ & $\begin{array}{l}0.12 \\
(0.5)\end{array}$ & $\begin{array}{c}0.12 \\
(0.25)\end{array}$ & $\begin{array}{l}0.12 \\
(0.5)\end{array}$ & $\begin{array}{l}0.062 \\
(0.25)\end{array}$ & $\begin{array}{l}0.12 \\
(1.0)\end{array}$ & $\begin{array}{l}0.062 \\
(0.12)\end{array}$ & $\begin{array}{c}0.062 \\
(0.5)\end{array}$ & $\begin{array}{c}2.0 \\
(>2.0)\end{array}$ & $\begin{array}{c}2.0 \\
(>2.0)\end{array}$ \\
\hline $7 c$ & $\begin{array}{c}0.031 \\
(0.062)\end{array}$ & $\begin{array}{c}0.015 \\
(0.031)\end{array}$ & $\begin{array}{c}0.015 \\
(0.015)\end{array}$ & $\begin{array}{c}0.015 \\
(0.062)\end{array}$ & $\begin{array}{c}0.015 \\
(0.062)\end{array}$ & $\begin{array}{l}0.031 \\
(0.12)\end{array}$ & $\begin{array}{c}0.015 \\
(0.031)\end{array}$ & $\begin{array}{c}0.015 \\
(0.031)\end{array}$ & $\begin{array}{c}1.0 \\
(>2.0)\end{array}$ & $\begin{array}{c}0.5 \\
(>2.0)\end{array}$ \\
\hline $7 d$ & $\begin{array}{c}0.031 \\
(0.062)\end{array}$ & $\begin{array}{l}0.031 \\
(0.12)\end{array}$ & $\begin{array}{l}0.031 \\
(0.12)\end{array}$ & $\begin{array}{l}0.12 \\
(1.0)\end{array}$ & $\begin{array}{l}0.031 \\
(0.12)\end{array}$ & $\begin{array}{l}0.12 \\
(0.5)\end{array}$ & $\begin{array}{l}0.062 \\
(0.12)\end{array}$ & $\begin{array}{l}0.062 \\
(0.25)\end{array}$ & $\begin{array}{l}0.12 \\
(0.5)\end{array}$ & $\begin{array}{l}0.12 \\
(0.5)\end{array}$ \\
\hline $7 e$ & $\begin{array}{l}0.062 \\
(0.12)\end{array}$ & $\begin{array}{c}0.031 \\
(0.062)\end{array}$ & $\begin{array}{c}0.031 \\
(0.062)\end{array}$ & $\begin{array}{c}0.12 \\
(0.25)\end{array}$ & $\begin{array}{c}0.031 \\
(0.062)\end{array}$ & $\begin{array}{c}0.12 \\
(250)\end{array}$ & $\begin{array}{c}0.031 \\
(0.062)\end{array}$ & $\begin{array}{l}0.062 \\
(0.12)\end{array}$ & $\begin{array}{c}0.5 \\
(1.0)\end{array}$ & $\begin{array}{c}0.5 \\
(2.0)\end{array}$ \\
\hline $7 f$ & $\begin{array}{l}0.031 \\
(0.12)\end{array}$ & $\begin{array}{l}0.031 \\
(0.12)\end{array}$ & $\begin{array}{l}0.031 \\
(0.12)\end{array}$ & $\begin{array}{l}0.12 \\
(0.5)\end{array}$ & $\begin{array}{c}0.015 \\
(0.062)\end{array}$ & $\begin{array}{l}0.12 \\
(0.5)\end{array}$ & $\begin{array}{l}0.031 \\
(0.12)\end{array}$ & $\begin{array}{c}0.015 \\
(0.062)\end{array}$ & $\begin{array}{c}0.5 \\
(1.0)\end{array}$ & $\begin{array}{c}0.5 \\
(2.0)\end{array}$ \\
\hline $7 \mathrm{~g}$ & $\begin{array}{l}0.12 \\
(0.5)\end{array}$ & $\begin{array}{l}0.12 \\
(1.0)\end{array}$ & $\begin{array}{l}0.12 \\
(0.5)\end{array}$ & $\begin{array}{l}0.12 \\
(1.0)\end{array}$ & $\begin{array}{l}0.062 \\
(0.25)\end{array}$ & NA & $0.12(0.5)$ & $\begin{array}{l}0.12 \\
(0.5)\end{array}$ & $\begin{array}{c}1.0 \\
(>2.0)\end{array}$ & $\begin{array}{c}1.0 \\
(>2.0)\end{array}$ \\
\hline $7 \mathrm{~h}$ & $\begin{array}{l}0.12 \\
(0.5)\end{array}$ & $\begin{array}{l}0.12 \\
(0.5)\end{array}$ & $\begin{array}{l}0.12 \\
(0.5)\end{array}$ & $\begin{array}{l}0.25 \\
(1.0)\end{array}$ & $\begin{array}{c}0.062 \\
(0.5)\end{array}$ & $\begin{array}{l}0.25 \\
(1.0)\end{array}$ & $0.12(0.5)$ & $\begin{array}{l}0.12 \\
(1.0)\end{array}$ & $\begin{array}{c}1.0 \\
(>2.0)\end{array}$ & $\begin{array}{c}0.5 \\
(>2.0)\end{array}$ \\
\hline $7 i$ & $\begin{array}{l}0.062 \\
(0.12)\end{array}$ & $\begin{array}{l}0.12 \\
(0.5)\end{array}$ & $\begin{array}{l}0.12 \\
(0.5)\end{array}$ & $\begin{array}{l}0.25 \\
(1.0)\end{array}$ & $\begin{array}{c}0.031 \\
(0.062)\end{array}$ & $\begin{array}{c}0.5 \\
(>2.0)\end{array}$ & $0.12(0.5)$ & $\begin{array}{l}0.12 \\
(1.0)\end{array}$ & $\begin{array}{c}1.0 \\
(>2.0)\end{array}$ & $\begin{array}{c}0.5 \\
(>2.0)\end{array}$ \\
\hline $7 j$ & $\begin{array}{c}0.031 \\
(0.062)\end{array}$ & $\begin{array}{l}0.062 \\
(0.12)\end{array}$ & $\begin{array}{c}0.031 \\
(0.062)\end{array}$ & $\begin{array}{c}0.12 \\
(0.25)\end{array}$ & $\begin{array}{c}0.031 \\
(0.062)\end{array}$ & $\begin{array}{l}0.12 \\
(0.5)\end{array}$ & $\begin{array}{l}0.062 \\
(0.25)\end{array}$ & $\begin{array}{l}0.062 \\
(0.12)\end{array}$ & $\begin{array}{c}0.5 \\
(>2.0)\end{array}$ & $\begin{array}{c}0.5 \\
(>2.0)\end{array}$ \\
\hline $7 \mathrm{k}$ & $\begin{array}{c}0.031 \\
(0.062)\end{array}$ & $\begin{array}{l}0.062 \\
(0.12)\end{array}$ & $\begin{array}{l}0.062 \\
(0.12)\end{array}$ & $\begin{array}{c}0.12 \\
(0.25)\end{array}$ & $\begin{array}{l}0.062 \\
(0.12)\end{array}$ & $\begin{array}{c}0.5 \\
(2.0)\end{array}$ & $\begin{array}{l}0.062 \\
(0.12)\end{array}$ & $\begin{array}{l}0.062 \\
(0.25)\end{array}$ & $\begin{array}{c}0.5 \\
(>1.0)\end{array}$ & $\begin{array}{c}0.5 \\
(>2.0)\end{array}$ \\
\hline 71 & $\begin{array}{c}0.015 \\
(0.015)\end{array}$ & $\begin{array}{l}0.062 \\
(0.25)\end{array}$ & $\begin{array}{l}0.062 \\
(0.12)\end{array}$ & $\begin{array}{l}0.25 \\
(1.0)\end{array}$ & $\begin{array}{l}0.12 \\
(0.5)\end{array}$ & $\begin{array}{l}0.25 \\
(1.0)\end{array}$ & $\begin{array}{l}0.25 \\
(1.0)\end{array}$ & $\begin{array}{l}0.12 \\
(0.5)\end{array}$ & $\begin{array}{c}0.5 \\
(>2.0)\end{array}$ & $\begin{array}{c}0.5 \\
(>2.0)\end{array}$ \\
\hline $7 m$ & $\begin{array}{l}0.12 \\
(1.0)\end{array}$ & $\begin{array}{c}0.062 \\
(0.5)\end{array}$ & $\begin{array}{c}0.062 \\
(0.5)\end{array}$ & $\begin{array}{l}0.062 \\
(0.12)\end{array}$ & $\begin{array}{l}0.12 \\
(0.5)\end{array}$ & $\begin{array}{c}0.5 \\
(1.0)\end{array}$ & NA & $\begin{array}{l}0.25 \\
(1.0)\end{array}$ & $\begin{array}{c}0.5 \\
(>2.0)\end{array}$ & $\begin{array}{c}1.0 \\
(>2.0)\end{array}$ \\
\hline $7 n$ & $\begin{array}{c}0.062 \\
(0.5)\end{array}$ & $\begin{array}{l}0.062 \\
(0.25)\end{array}$ & $\begin{array}{l}0.062 \\
(0.25)\end{array}$ & $\begin{array}{c}0.062 \\
(0.5)\end{array}$ & $\begin{array}{l}0.12 \\
(0.5)\end{array}$ & $\begin{array}{c}0.5 \\
(2.0)\end{array}$ & $0.12(0.5)$ & $\begin{array}{l}0.12 \\
(1.0)\end{array}$ & $\begin{array}{c}1.0 \\
(>2.0)\end{array}$ & $\begin{array}{c}0.5 \\
(>2.0)\end{array}$ \\
\hline 70 & $\begin{array}{c}0.062 \\
(0.5)\end{array}$ & $\begin{array}{c}0.062 \\
(0.5)\end{array}$ & $\begin{array}{l}0.062 \\
(0.25)\end{array}$ & $\begin{array}{l}0.25 \\
(0.5)\end{array}$ & $\begin{array}{l}0.12 \\
(0.5)\end{array}$ & $\begin{array}{c}0.5 \\
(2.0)\end{array}$ & $0.12(1.0)$ & $\begin{array}{l}0.12 \\
(1.0)\end{array}$ & $\begin{array}{c}1.0 \\
(>2.0)\end{array}$ & $\begin{array}{c}0.5 \\
(>2.0)\end{array}$ \\
\hline Ciprofloxacin & $\begin{array}{c}0.0009 \\
(0.0019)\end{array}$ & $\begin{array}{l}0.0005 \\
(0.0009\end{array}$ & $\begin{array}{c}0.0009 \\
(0.0019)\end{array}$ & $\begin{array}{c}0.0019 \\
(0.0039)\end{array}$ & $\begin{array}{l}0.00097 \\
(0.0019)\end{array}$ & $\begin{array}{c}0.0019 \\
(0.0039)\end{array}$ & $\begin{array}{c}0.0005 \\
(0.0009)\end{array}$ & $\begin{array}{c}0.0009 \\
(0.0019)\end{array}$ & - & - \\
\hline Nystatin & - & - & - & - & - & - & - & - & $\begin{array}{c}0.0039 \\
(0.0078)\end{array}$ & $\begin{array}{l}0.0078 \\
(0.015)\end{array}$ \\
\hline
\end{tabular}

MIC: Minimum inhibitory concentration; MBC: Minimum bactericidal concentration; NA: not active; a: B. subtilis; b: S. aureus; c: B. licheniformis; d: P. aeruginosa; e: E. coli; $\mathrm{f}:$ P. mirabilis; g : S. typhimurium; h: E. aerogenes; i: C. albicans; $\mathrm{j}$ : A. niger

coefficient " $r$ " of significantly correlated results are shown in the figure. It could be seen in Figure 1(a) that MICs are significantly correlated for gram-positive microbes and highest correlation coefficient $(r=0.9877)$ was found between MIC data of S. aureus and B. subtilis. Similarly high correlation among MICs of most of the gram-negative microbes was found as shown by Figure 1 (b) revealing almost same level of effectiveness of synthesized compounds against them. Similarly difference in the behavior of the compounds against tested fungal strains is depicted by Figure 1(c) that shows poor correlation between observed MICs. It could be inferred from these graphs that tested compounds exhibited broad spectrum activity against tested bacterial strains while inhibited fungal strains weakly. Furthermore the histogram plots in the diagonal give us insight regarding probability 


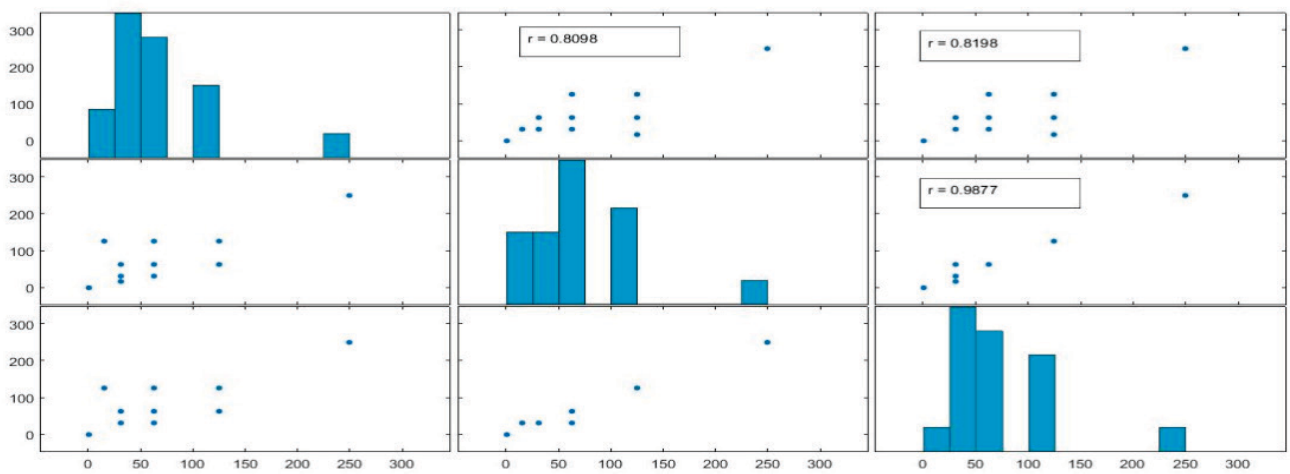

$\left(a^{\prime}\right)$

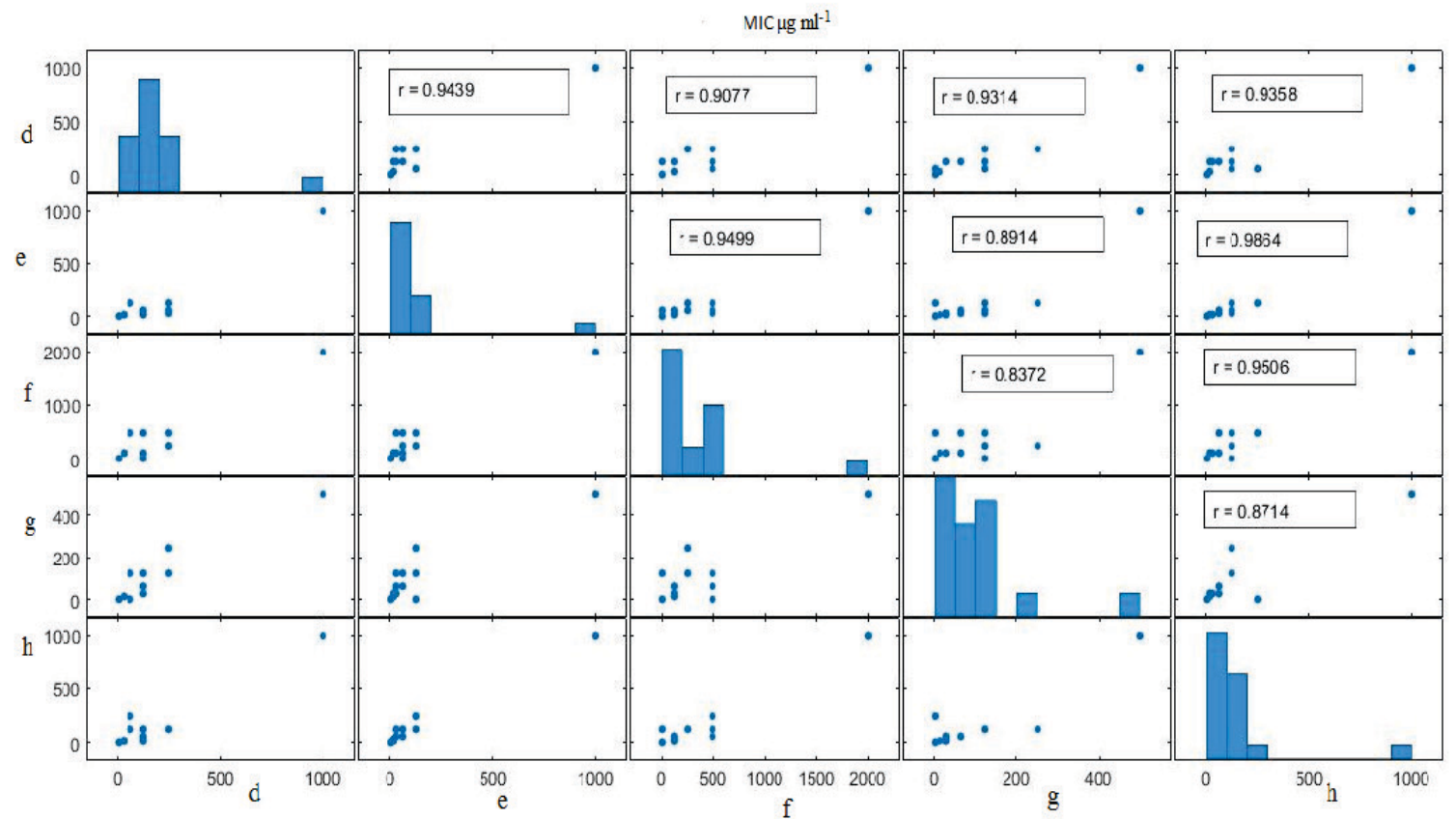

$\left(b^{\prime}\right)$

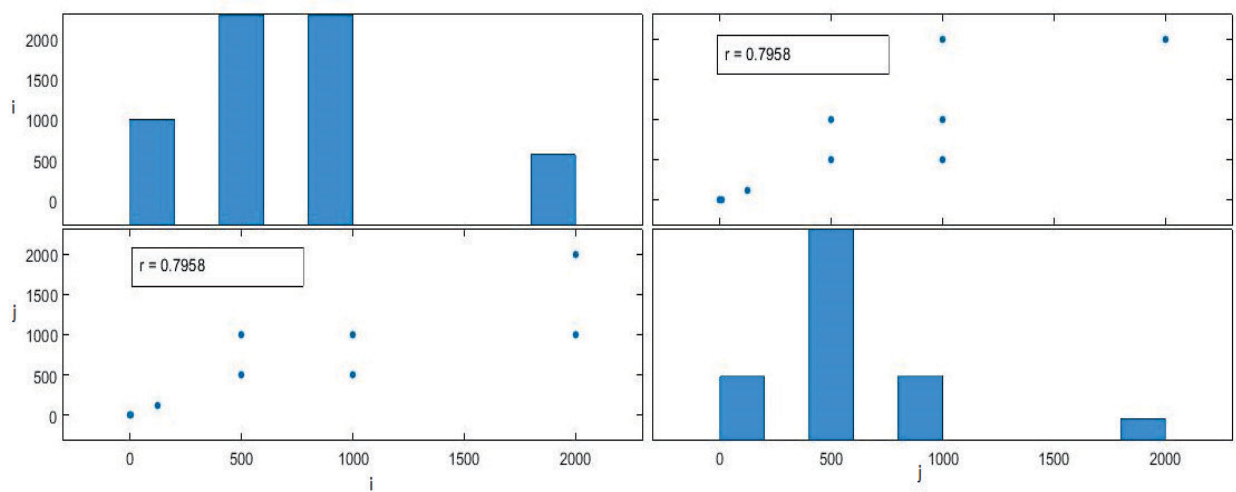

$\left(c^{\prime}\right)$

Figure 1. Polymetrix graphs showing MICs scatter plots and corresponding correlation coefficient ' $r$ ' of $\left(a^{\prime}\right)$ : Gram-positive bacteria; $\left(b^{\prime}\right)$ : Gram-negative bacteria; $\left(c^{\prime}\right)$ : Fungal strains. 
distribution of MICs for each microbe. The height of each bar shows the frequency of a particular MIC appearing in the data set for different compounds.

$M B C$ is the lowest concentration of the antibiotic required to kill the microbes. Analysis of Table 2 reveals that there are many compounds that were effective on the basis of MICs but failed to prove potency against the tested microbes on the basis of MBCs.

Weibull distribution approach is used to give an overview of microbial resistance towards tested compounds via distribution probability of MBCs. The points on the plot exhibit the probability distribution of each $M B C$ value for all the tested microbes in the data set. In Figure 2 $x$-axis represents the MBCs from a range of 0.0004 to 1.0 $\mathrm{mg} \mathrm{mL}-1$ and $y$-axis represents probability of their occurrence for each microbe. The slope of the best-fit straight line is determined through the data using linear regression. We can estimate all the statistical properties through this plot e.g. skewness of the data, parameter estimate value, median, microbial resistance towards tested compounds etc. For example in gram-positive microbes probability distribution of $\mathrm{MBC}$ value $0.062 \mathrm{mg}$ $\mathrm{mL}^{-1}$ is highest i.e. $0.294 \mathrm{~s}$ for $B$. subtilis whereas $0.5 \mathrm{mg}$ $\mathrm{mL}^{-1}$ showed highest distribution for $S$. aureus and $B$. licheniformis. Figure 2(c) shows that gram-negative strains were more resistant against GA derivatives as most frequently observing $\mathrm{MBCs}$ are 0.5 and $1.0 \mathrm{mg} \mathrm{mL}^{-1}$. For the fungal strains, most of the MBCs were not detected as they did not fall in the tested concentration range.

Mode of antimicrobial activity is represented in Figure 3. Generally an antibiotic is regarded bacteriostatic if $\mathrm{MBC} / \mathrm{MIC}$ ratio is greater than $\mathrm{MIC \times 3}{ }^{[28]}$ Heatmap graphs of data revealed that mode of action of many compounds was bactericidal as MBCs were two fold higher than MICs while derivatives having ratio three or higher folds were bacteriostatic in nature.

Figure $4\left(a^{\prime}\right)$ presents the thin plate interpolant for gram-positive microbes. The slope of plate is relatively increasing for increasing $\mathrm{MBC}$, since the ratio increases likewise. A good percentage of points lie on or below the plane $\mathrm{MBC} / \mathrm{MIC}=2$. The graph $4\left(b^{\prime}\right)$ presents the thin plate interpolant for gram-negative microbes. The graph has a tale towards the increasing values of MIC. This shows that the spread is rational with respect to increasing values of MBC but irrational for increasing values of MIC. A good percentage of points lie on or below the plane $\mathrm{MBC} / \mathrm{MIC}=$ 4. The graph $4\left(c^{\prime}\right)$ presents the thin plate interpolant for the tested fungal strains. There is a twist in the plate relative to increasing values of $\mathrm{MBC}$. Only a few points lie on or below the plane $\mathrm{MBC} / \mathrm{MIC}=2$. From the three dimensional presentation above, we can see that the $\mathrm{MBC} / \mathrm{MIC}$ ratio is lowest for fungal microbes. For other two cases, its values ranged from 1 till 8 . The spread of the data relative to MIC,

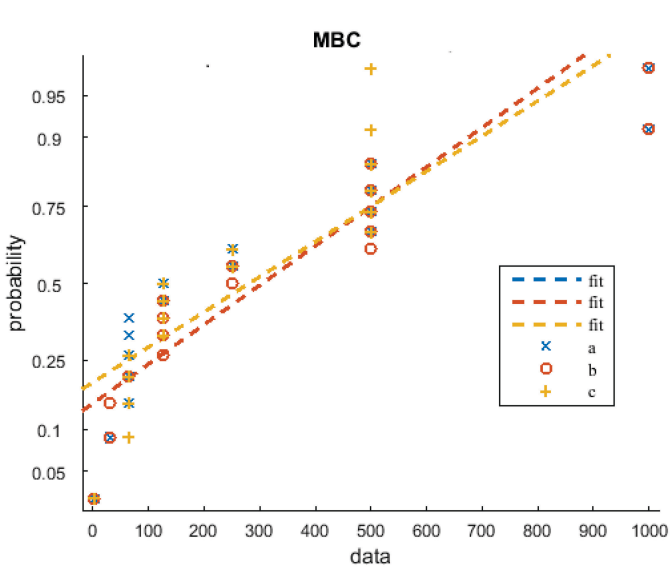

$\left(a^{\prime}\right)$

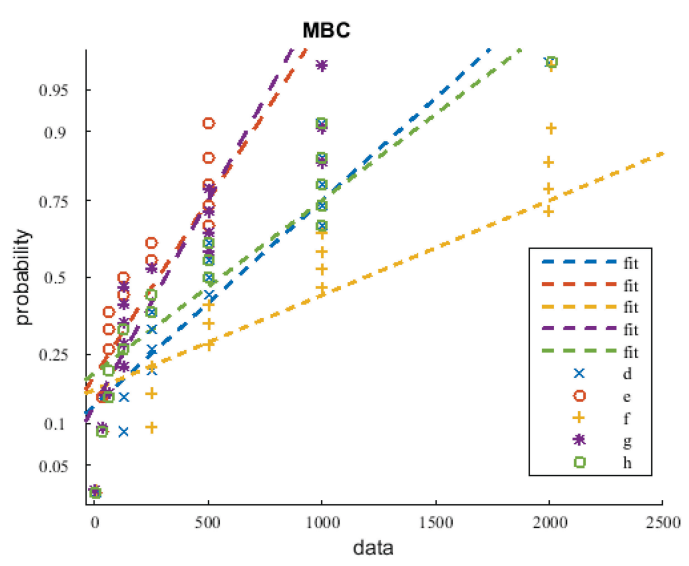

$\left(b^{\prime}\right)$

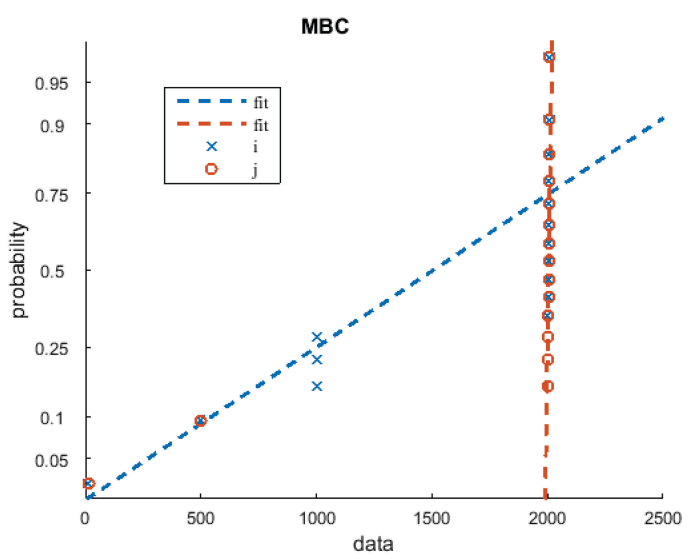

$\left(c^{\prime}\right)$

Figure 2. Weibull distribution graphs of MBCs of $\left(a^{\prime}\right)$ : Grampositive bacteria; $\left(b^{\prime}\right)$ : Gram-negative bacteria; $\left(c^{\prime}\right)$ : Fungal strains

$\mathrm{MBC}$ and their corresponding ratio helps to depict the relation between the MIC and MBC values of each microbe. 


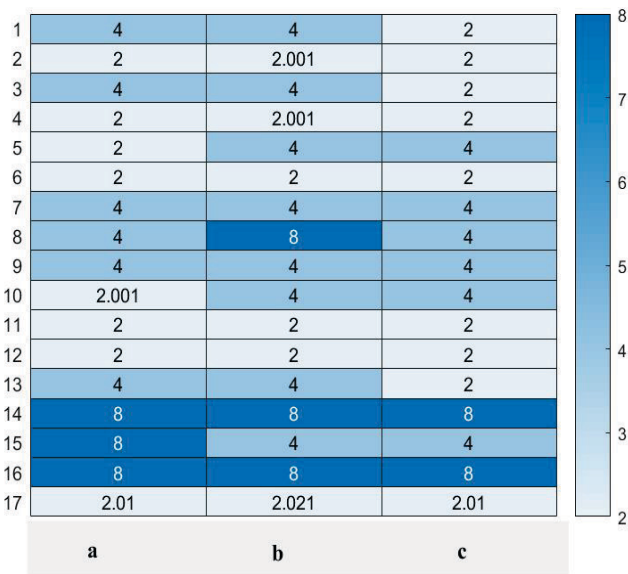

$\left(a^{\prime}\right)$

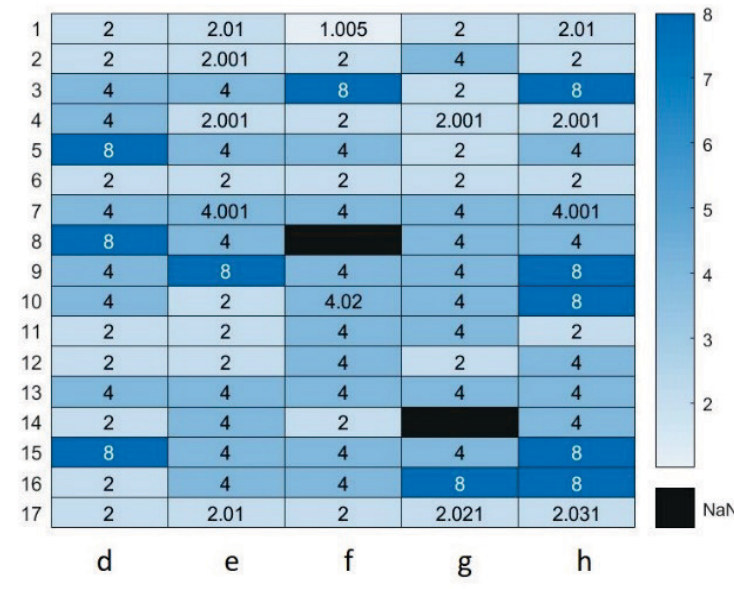

$\left(b^{\prime}\right)$

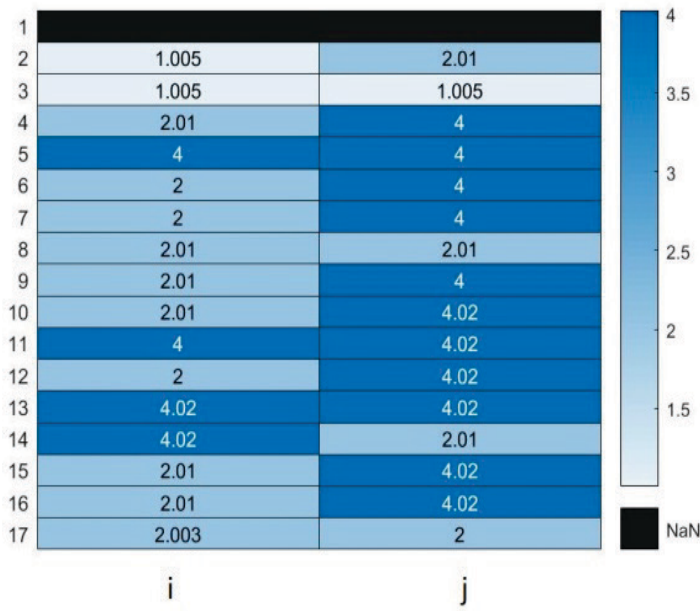

$\left(c^{\prime}\right)$

Figure 3. Bactericidal/bacteriostatic activity of the synthesized compounds 7a-7o against $\left(a^{\prime}\right)$ :Gram-positive bacteria; $\left(b^{\prime}\right)$ :Gramnegative bacteria; $\left(c^{\prime}\right)$ : Fungal strains.

The surface plotted presents the deviation of the data points relative to increasing values of MIC and MBC. In $4\left(a^{\prime}\right)$ the data points are nicely scattered, whereas in case $4\left(b^{\prime}\right)$, the spread is complex and in case $4\left(c^{\prime}\right)$ it is hard to predict the relation between MIC and MBC from their surface plot.

\section{Structure-Activity Relationship}

From analysis of antimicrobial activity results of synthesized gallic acid derivatives, following assumptions regarding structure activity relations can be made:

i. Structural modifications in parent compound have resulted in enhanced biological activities specifically against bacterial strains. Poor antifungal activity of lead as well as derivatives is in accordance to Goker et al.[29] work that reported the ineptness of introduction of amide, carboxylic or ester linkage for antifungal power enhancement.

ii. In general, substituent grafting had much more pronounced impact on therapeutic value of the synthesized compounds than mere introduction of ester linkage in the parent molecule. Activity pattern observed in this study indicated that electronwithdrawing substituent exhibited higher activity against tested microbial strains than electrondonating substituent. These findings are in consistent with the work of Sherma et al. ${ }^{[30]}$

iii. Halogen substituted, particularly, chloro derivatives of alkyl esters proved to be more potent 


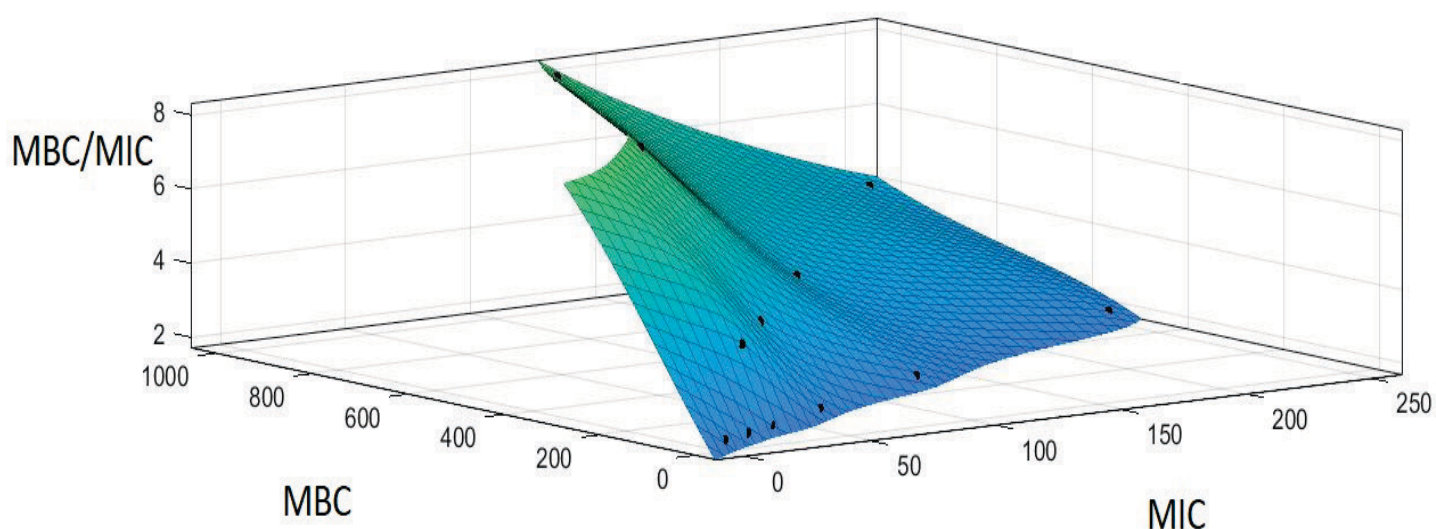

$\left(a^{\prime}\right)$

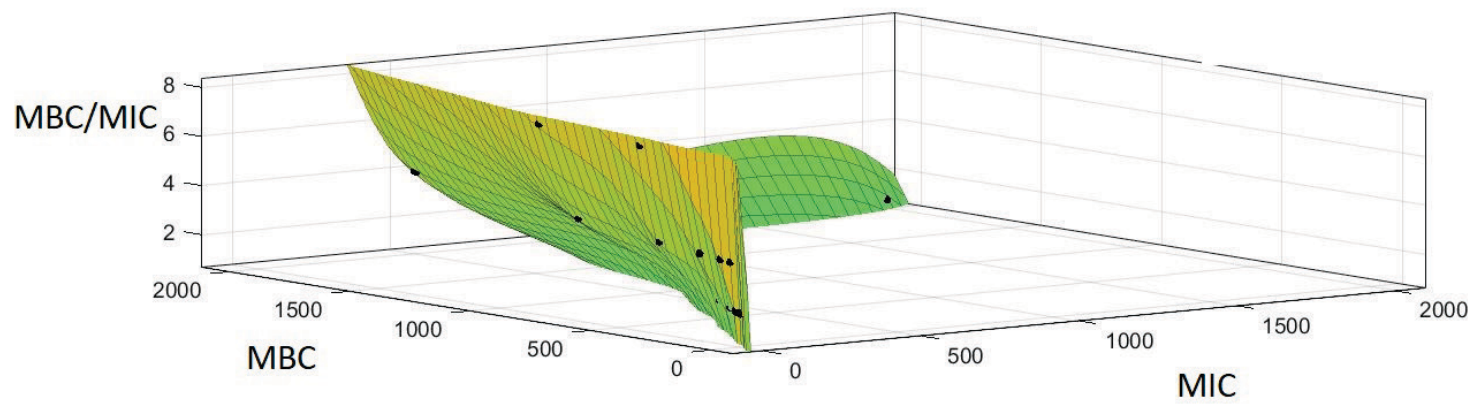

$\left(b^{\prime}\right)$

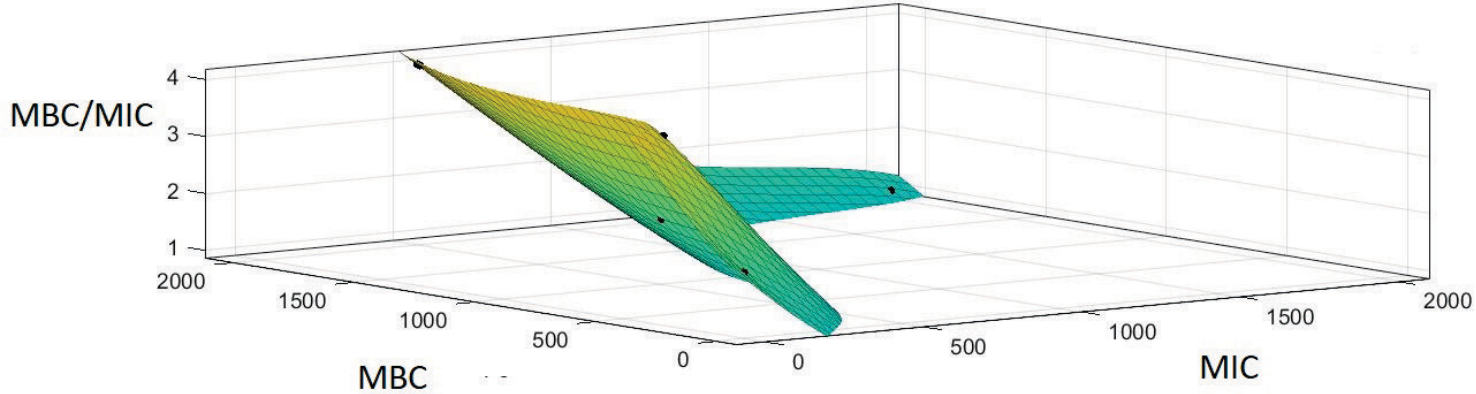

$\left(c^{\prime}\right)$

Figure 4. 3D surface plots showing interrelation of $M I C, M B C$ and $M B C / M I C$ values for $\left(a^{\prime}\right)$ : Gram-positive bacteria; $\left(b^{\prime}\right)$ : Gramnegative bacteria; $\left(c^{\prime}\right)$ : Fungal strains.

antibacterial agent. Thus compounds $7 a$ and $7 c$ exhibited highest broad spectrum activity though they were not handy against tested fungi. Apparently ortho or para position of substituent had no significant impact on activity.

iv. Aryl esters exhibited much better antimicrobial profile as compared to GA. Comparison of data suggested that whether substituted or unsubstituted both aryl moieties played vital role in improving the antimicrobial potential. It is assumed that aromatic ring enhances the drug binding with target by increasing its lipophilicity.

v. It could be deduced from the results that structural requirements are different for drug binding to bacterial and fungal targets as only $\mathrm{NO}_{2}$ substituted compound have shown reasonable antifungal activity among all the tested compounds. These results are supported by literature. ${ }^{[31]}$ 
Table 4. In vitro DPPH scavenging, ABTS+decolorization, and anti-lipid peroxidation activities of gallic acid esters (7a-7o)

\begin{tabular}{|c|c|c|c|}
\hline \multicolumn{4}{|c|}{ Half Efficiency Conc. $\left(I C_{50}\right)^{a}$} \\
\hline Compounds & $\begin{array}{l}\text { DPPH scavenging activity } \\
\qquad\left(\mu \mathrm{g} \mathrm{ml}^{-1}\right)\end{array}$ & $\begin{array}{l}\mathrm{ABTS}^{+} \text {decolorization } \\
\text { activity }\left(\mu \mathrm{g} \mathrm{ml}^{-1}\right)\end{array}$ & $\begin{array}{l}\text { Anti-lipid peroxidation activity } \\
\qquad\left(\mathrm{mg} \mathrm{ml}^{-1}\right)\end{array}$ \\
\hline 1 & $2.38 \pm 0.05^{b}$ & $1.60 \pm 0.08^{b}$ & $2.22 \pm 0.02^{b}$ \\
\hline $7 a$ & $1.33 \pm 0.10$ & $1.19 \pm 0.09$ & $0.24 \pm 0.04$ \\
\hline $7 \mathrm{~b}$ & $1.45 \pm 0.11$ & $1.44 \pm 0.20$ & $0.26 \pm 0.03$ \\
\hline $7 c$ & $1.43 \pm 0.07$ & $1.35 \pm 0.07$ & $0.21 \pm 0.02$ \\
\hline $7 d$ & $1.12 \pm 0.13$ & $1.14 \pm 0.18$ & $0.33 \pm 0.01$ \\
\hline $7 e$ & $1.37 \pm 0.15$ & $1.25 \pm 0.05$ & $0.25 \pm 0.02$ \\
\hline $7 f$ & $1.23 \pm 0.06$ & $1.21 \pm 0.23$ & $0.24 \pm 0.03$ \\
\hline $7 \mathrm{~g}$ & $18.7 \pm 0.65$ & $1.93 \pm 0.08$ & $0.48 \pm 0.01$ \\
\hline $7 \mathrm{~h}$ & $19.4 \pm 0.88$ & $1.54 \pm 0.25$ & $0.41 \pm 0.13$ \\
\hline $7 i$ & $19.9 \pm 0.43$ & $1.65 \pm 0.55$ & $0.44 \pm 0.02$ \\
\hline $7 \mathrm{j}$ & $1.45 \pm 0.04$ & $1.51 \pm 0.07$ & $0.20 \pm 0.40$ \\
\hline $7 \mathrm{k}$ & $57.7 \pm 0.60$ & $9.93 \pm 0.40$ & $0.50 \pm 0.01$ \\
\hline 기 & $17.8 \pm 0.68$ & $1.46 \pm 0.04$ & $0.40 \pm 0.02$ \\
\hline $7 m$ & $18.3 \pm 0.20$ & $2.00 \pm 0.06$ & $0.45 \pm 0.01$ \\
\hline $7 n$ & $18.4 \pm 0.44$ & $1.26 \pm 0.09$ & $0.39 \pm 0.01$ \\
\hline 70 & $18.7 \pm 0.30$ & $1.20 \pm 0.04$ & $0.39 \pm 0.11$ \\
\hline trolox & $6.17 \pm 0.02$ & $3.86 \pm 0.03$ & $0.08 \pm 0.03$ \\
\hline
\end{tabular}

a $\mathrm{IC}_{50}$ is the conc. of the compound that causes $50 \%$ decline of initial DPPH, ABTS'+ or TBARS conc.;

b Data are mean $(n=3) \pm \operatorname{SD}(n=3, p<0.05)$.

\section{Antioxidant Activity Evaluation}

The antioxidant capacity of the synthesized derivatives was evaluated using ET and HAT antioxidant assays. The disagreement between antioxidant capacities obtained from different assays indicates that each class of assays determines different aspects of antioxidant capacity by employing different radicals and reaction mechanism.

Results of electron transfer based assay i.e. DPPH radical scavenging and ABTS decolorization assay are shown in Table 4. All the compounds exhibited different propensity towards free radical quenching, the maximum values in DPPH assay were found for $\mathbf{7 d}$ and $\mathbf{7 f}$. The calculated $\mathrm{IC}_{50}$ values for compounds varied from 1.12 to $57.7 \mu \mathrm{g} \mathrm{ml}^{-1}$. It was found that many derivatives $(\mathbf{7 a - 7 f}, \mathbf{7 j})$ were more active than lead in DPPH quenching and showed much low $\mathrm{IC}_{50}$ values. For ABTS assay $\mathrm{IC}_{50}$ values ranged from 1.19 to $9.93 \mathrm{\mu g} \mathrm{ml}^{-1}$. Most efficient compounds with highest values were $\mathbf{7 d}$ and $\mathbf{7 a}$. In both the assays7k showed the poorest results with highest $I_{50}$ values. Similarity of the results can be explained as in both of these assays reaction mechanism is based on electron transfer and measurement of antioxidant potential is associated with exogenous reduction of free radicals such as DPPH• and ABTS+•. A careful analysis of results reveals that grafting a substituent on ester moiety had significant impact on radical quenching capacity of the synthesized compounds. Data shows that introduction of halogen atom or nitro group enhanced the built-in antioxidant power many folds. It is speculated that electron-withdrawing character of the substituent might have augmented the stability of phenoxide ion formed during the radical quenching process. Electron -withdrawing substituent cut down the electron density on pyrogallol moiety and tend to stabilize the phenoxide ion formed, resulting in higher antioxidant capacity. Inversely electron donating groups destabilize the phenoxide ion and hence decline antioxidant power of the compound.

In anti-lipid peroxidation assay, results showed that compounds $\mathbf{7 j}, \mathbf{7 c}$ and $\mathbf{7 f}$ provided highest protection against peroxidation with lowest production of malondialdehyde (MDA). In comparison to gallic acid, almost all the derivatives generated a significant decrease in MDA concentration. A significant difference in shielding against lipid peroxidation may be attributed to the structural differences in derivatives. It was found the compounds bearing electron-withdrawing substituent displayed much better protection against lipid damage; hence can impart better therapeutic benefits against ROS mediated lipid oxidation. This assay is based on hydrogen atom transfer (HAT) method that measure antioxidant potency on the basis of capturing endogenous radicals acting on oxidized targets. Though reaction mechanism is complex but inherent advantage of this assay is involvement of physiological radicals in contrast to ET assays. These findings show significant potential of some of the gallic acid esters as valuable natural antioxidant molecules. 


\section{CONCLUSIONS}

In conclusion, a series of new gallic acid esters 7a-7o was synthesized. Pharmacological assessment was undertaken to evaluate the impact of structural modification and substituent for their antibiotic and antioxidant potency. In general bacteria were more sensitive than fungal strains on these compounds. Most of the derivatives displayed moderate to good broad spectrum activity towards tested microbial panel but did not express substantial action against fungal strains. Most effective compounds found were $\mathbf{7 a}, \mathbf{7 c}$ and $\mathbf{7 d}$. Significant enrichment of antimicrobial power of synthesized compounds can be attributed to the presence of electron-withdrawing groups. Particularly, grafting of chloro group amplified the inhibitory action many folds. Similar pattern was observed in antioxidant activity as it was much upgraded by implanting electron withdrawing substituent onto gallic acid architecture. In comparison to inactive lead, quite high MICs of derivatives against fungal strains indicate further structural modification of these compounds for improved antifungal activity.

Conflict of Interest. The authors declare that there is no conflict of interest.

Declaration of Interest. None.

Funding Information. The research is partially funded by HEC-SRGP grant.

Acknowledgment. The authors gratefully acknowledge Professor David G I Kingston, Department of Chemistry, Virginia Polytechnic Institute and state University, Virginia, USA for assisting in synthesis and Dr Quratulain Syed, DG PCSIR Labs. Complex Lahore, Pakistan for generously providing the microbial strains and assisting in antimicrobial activity evaluation.

\section{REFERENCES}

[1] H. Göker, C. Kuş, D. W. Boykin, S. Yildiz, N. Altanlar, Bioorg. Med. Chem. 2002, 10(8), 2589.

[2] D. G. Brown, T. Lister, T. L. May-Dracka, Bioorg. Med. Chem. Lett. 2014, 24(2), 413.

[3] G. M. Cragg, P. G. Grothaus, D. J. Newman, J. Nat. Prod. 2014, 77(3), 703.

[4] T. T. Reed, Free Radical Biol. Med. 2011, 51(7), 1302.

[5] S. Reuter, S. C. Gupta, M. M. Chaturvedi, B. B. Aggarwal, Free Radical Biol. Med. 2010, 49(11), 1603.

[6] K. Sugamura, J. F. Keaney, Free Radical Biol. Med. 2011, 51(5), 978.

[7] D. Krishnaiah, R. Sarbatly, R. Nithyanandam, Food Bioprod. Process 2011, 89(3), 217.
[8] Z. Sroka, W. Cisowski, Food Chem. Toxicol. 2003, 41(6), 753.

[9] I. Kubo, P. Xiao, K. I. Fujita, Bioorg. Med. Chem. Lett. 2001, 11(3), 347.

[10] A. Jadon, M. Bhadauria, S. Shukla, J. Ethnopharmacol 2007, 109(2), 214.

[11] Z. Lu, G. Nie, P. S. Belton, H. Tang, B. Zhao, Neurochem. Int. 2006, 48(4), 263.

[12] Y. Ren, K. Himmeldirk, X. Chen, J. Med. Chem. 2006, 49(9), 2829.

[13] H. U. Gali, E. M. Perchellet, D. S. Klish, J. M. Johnson, J. P. Perchellet, Carcinogenesis 1992, 13(4), 718.

[14] C. Dalla Pellegrina, G. Padovani, F. Mainente, G. Zoccatelli, G. Bissoli, S. Mosconi, G. Veneri, A. Peruffo, G. Andrighetto, C. Rizzi, R. Chignola, Cancer Lett. 2005, 226(1), 17.

[15] R. Krogh, R. A. Yunes, A. D. Andricopulo, I/ Farmaco 2000, 55(11-12), 730.

[16] N. Oku, M. Matsukawa, S. Yamakawa, T. Asai, S. Yahara, F. Hashimoto, T. Akizawa, Biol. Pharm. Bull 2003, 26(9), 1235.

[17] K. Murakam, M. Ito, H. H. Htay, R. Tsubouchi, S. Iwata, M. Yoshino, Biomed. Res. 2000, 21, 291.

[18] C. Locatelli, P. C. Leal, R. A. Yunes, R. J. Nunes, T. B. Creczynski-Pasa, Chem. Biol. Interact. 2009, 181, 175.

[19] A. S. Shedge, P. P. Wadgaonkar, A. K. Lele, M. V. Badiger, J. Polym. Sci. B 2010, 48, 1054.

[20] M. Nakazono, L. Ma, K. Zaitsu, Tetrahedron Lett. 2002, 43, 8185.

[21] E. Nomura, A. Hosoda, H. Morishita, A. Murakami, K. Koshimizu, H. Ohigashi, H. Taniguchi, Bioorg. Med. Chem. 2002, 10, 1069.

[22] D. I. Jung, J. H. Song, E. H. Shin, Y. Y. Kim, D. H. Lee, S. K. Choi, J. T. Hahn, Bull. Korean Chem. Soc. 2010, 31, 1031.

[23] R. Cecotti, E. Carpana, L. Falchero, R. Paoletti, A. Tava, Chem. Biodivers. 2012, 9, 359.

[24] P. Jayaraman, M. K. Sakharkar, C. S. Lim, T. H. Tang, K. R. Sakharkar, Int. J. Biol. Sci. 2010, 556.

[25] M. S. Blois, Nature 1958, 181, 1199.

[26] R. Re, N. Pellegrini, A. Proteggente, A. Pannala, M. Yang, C. Rice-Evans, Free Radical Boil. Med. 1999, 26, 1231.

[27] B. Halliwell, J. M. C. Guttridge, Free Radical Boil. Med. $19892^{\text {nd }}$ ed., 125.

[28] A. Scalbert, Phytochemistry 1991, 30, 3875.

[29] S. Emami, M. Falahati, A. Banifatemi, A. Shafiee, Bioorg. Med. Chem. 2004, 12, 5881.

[30] P. Sharma, N. Rane, V. K. Gurram, Bioorg. Med. Chem. Lett. 2004, 14(16), 4185.

[31] P. Kumar, B. Narasimhan, D. Sharma, Arkivoc 2008, 13, 159. 